\title{
Fragility Analysis of Rectangular and Circular Reinforced Concrete Columns under Bidirectional Multiple Excitations
}

\author{
Mohammad Reza Salami ${ }^{a}$, Ebrahim Afsar Dizaj ${ }^{b}$, Mohammad Mehdi Kashanic \\ aLecturer in Engineering, School of Engineering and the Built Environment, Birmingham City University, B5 5JU, United \\ Kingdom (corresponding author), Email: mohammad.salami@bcu.ac.uk \\ ${ }^{b}$ Assistant Professor, Department of Civil Engineering, Azarbaijan Shahid Madani University, Tabriz, Iran, Email: \\ ebrahim.afsardizaj@azaruniv.ac.ir \\ ${ }^{c}$ Associate Professor, Faculty of Engineering and Physical Sciences, University of Southampton, Southampton, SO17 1BJ, \\ United Kingdom, Email: mehdi.kashani@soton.ac.uk
}

\begin{abstract}
:
This paper presents a numerical investigation on seismic performance of reinforced concrete (RC) cantilever columns under unidirectional and bidirectional excitations. The influence of cross-sectional geometry and multiple excitations have been examined in this study. An advanced nonlinear finite element model is employed to model different failure modes of RC columns under seismic excitation. The model simulates degradation of materials under cyclic loading, including inelastic buckling and low-cycle fatigue degradation of longitudinal reinforcement. A series of monotonic pushover and incremental dynamic analyses (IDA) are conducted on hypothetical rectangular and circular columns. Proposing a unique algorithm, an existing inclusive damage index is implemented to quantify the different sources of damage including flexural, shear and reinforcement slippage damage under bidirectional excitation. Ground motion records are carefully selected using conditional mean spectrum (CMS) to generate as-recorded real mainshock and aftershock (MSAS) sequences. Results show that multiple bidirectional excitations significantly increase the damage that accumulates in RC columns. Moreover, inelastic buckling and low-cycle fatigue degradation of longitudinal bars have an evident contribution to the failure of RC columns. It is also found that the rectangular column is more prone to collapse under bidirectional loading in comparison to circular section. The analyses results show that the impact of bidirectional excitation on the seismic performance of the studied cantilever columns is considerable. This implies that seismic performance assessment of RC structures using unidirectional excitation can be biased.
\end{abstract}

Keywords: reinforced concrete, bidirectional loading, multiple excitations, low-cycle fatigue

\section{Introduction}

\subsection{Research background}

The seismic performance of reinforced concrete (RC) structures under unidirectional loading has been studied for several years using experimental studies [1-5] and analytical methods [6-10]. Despite the three dimensional and random characteristics of ground motions, most of the current knowledge is based on unidirectional 
loading [11-12]. Available models have proved to be accurate in simulating flexural, shear and axial behavior of 2D RC frames. However, the nonlinear dynamic behavior of RC columns/bridge piers under bidirectional loading is still an ongoing research. Many researchers were aware of the potential significance of bidirectional bending, and have demonstrated this by running experimental and numerical investigations. For instance, Solberg et al. [13]; Khaled et al. [14]; Rodrigues et al. [5, 12, 15-17 ]; Nojavan et al. [18]; Han et al. [19]; Lee et al. [20]; Raza et al. [21] used cyclic testing, whereas Nakayama et al. [22-23]; Hachem et al. [24]; Galé-Lamuela et al [25] used shake table testing and Park et al. [26]; Kitajima et al. [27]; Zeris et al. [28]; Lu et al. [29] performed numerical analyses. The main conclusion by reviewing the above-mentioned literature is that bidirectional loading decreases the maximum strength and stiffness of the RC columns.

The ultimate displacement capacity of RC members associated with bidirectional loading is still not clear and the current literature is inadequate. As reported by Hachem et al. [24], based on their experimental study it is not apparent that bidirectional loading leads to higher displacement capacity especially for wellconfined columns under low axial load intensities. Conducting uni- and bidirectional shaking table tests, they found that peak bidirectional response is similar to that predicted unidirectionally, but that increased demand might be observed in the short period range. They also reported that bidirectional loading has a tendency to increase the residual displacements and it is strongly dependent on axial load ratio.

In another study, Rodrigues et al. [5, 12, 15-17 ] conducted extensive uni- and bidirectional cyclic tests and suggested that specific damage occurs for lower drift demands for RC members under bidirectional loading when compared to unidirectional loading. In particular, they reported that cover concrete cracking for columns tested under bidirectional loading occurs at similar drift demand for unidirectional tests. However, spalling in bidirectional tests happens at drift in the range of 50-75\%, bar bucking occurs at a drift between $65 \%$ and $75 \%$ of that observed in the unidirectional test. In general, the ultimate ductility is considerably lower in columns under bidirectional loading and this effect is more prominent in rectangular columns (50\% to $75 \%$ lower in the weak direction and approximately 35\% lower in the strong direction). Similarly, in a numerical study, Sengupta et al. [30], found that bidirectional loading can amplify the response in the short period systems up to $30 \%$ for ground motions records with forward directivity characteristics and as high as $50 \%$ for stiff systems under fling pulses ground motions.

Keeping in mind that the ultimate displacement is currently a desired engineering demand parameter (EDP), the challenge of bidirectional loading in practice have been simplified by so-called 30\% [31-33] and 40\% [34-37] combination rules. The idea behind this method is to apply each component of a ground motion along the principal axis of the structures separately. The peak unidirectional deformation is calculated based on the maximum deformation in the entire time history analysis plus 30\% of the maximum response in the orthogonal direction. A review and applicability of the method have been reported in [14, 37-38].

Reviewing the experimental studies reported in the current literature show that concrete cover spalling, bar buckling, low-cycle fatigue, loss of confinement and bond-slip, are the main factors increasing the 
stiffness/strength degradation of RC columns under bidirectional excitation. Few experimental studies have pointed out the impact of bar buckling and fatigue for RC columns under bidirectional loading [14, 18 and 24]. For instance, Hachem et al. [24] reported that low-cycle fatigue can have a significant contribution to the failure of columns under bidirectional loading. They reported that the fatigue damage index is very small for periods longer than 1 second; conversely, the fatigue index may be double (on average) for short period RC columns under bidirectional loading. In their experimental study they found that bar buckling followed by spiral fracture is more common for RC columns under unidirectional loading, however, columns under bidirectional loading tend to fracture first, with less bar buckling. They concluded that in the specific specimen that experienced bar fracture, low-cycle fatigue had more contribution than bar buckling and loss of confinement. The significance of bar buckling for RC columns under bidirectional loading is also observed by Khaled et al. [14]. They found that under large displacements, buckling of corner bars may happen. In addition to low-cycle fatigue and bar buckling, Hachem et al. [24] also observed that the deformation due to pullout of the longitudinal reinforcement from the foundation contributed to about $30 \%$ of the peak displacement for all the specimens they have tested.

Considering the important contribution of low-cycle fatigue and buckling of longitudinal reinforcements in damage of RC buildings, Salami et al. [39] conducted an investigation of seismic performance of low-rise RC buildings under multiple excitations. They found that an escalation of damage in RC columns due to low-cycle fatigue is probable. The accumulation of damage and degradation in the structure due to the mainshock and the following aftershocks has also been reported by Faisal et al. [40]; Ebrahimian et al. [41]; Goda et al. [42]; Raghunandan et al. [43]; Jeon et al. [44]; Kashani et al. [45]. However, all the above-mentioned studies used 2D structural models excited under unidirectional loading, which is in contradiction with the bidirectional nature of ground motions and 3D geometry of buildings. The bidirectional load interaction leads to increased elongation of the structural period and pronounced increase in bond-slip and shear displacement [30] which is more severe for short-period structures. Damage accumulation under mainshock and aftershock can be increased significantly under bidirectional loading in particular for stiff systems. Hence, this paper aims to explore and quantify the impact of bidirectional loading on RC columns under multiple excitations.

Reviewing the current literature, there is a significant shortcoming in the assessment of RC columns under bidirectional loading. In particular, numerical simulations under bidirectional base excitations. One major challenge that limits the quantity of research in this area, is the popularity of lumped plasticity models for RC structures. As the response in both directions is uncoupled, the bidirectional loading is irrelevant and therefore have been neglected so far. In contrast, fibre beam-column modelling is the right approach for bidirectional loading, especially that the axial and bidirectional flexural load interaction is considered realistically. Integrating low-cycle fatigue, bar buckling, and bond-slippage in bidirectional excitation of RC columns and developing fragility curves to highlight the significance of bidirectionally loading is the main incentive for this study to enrich the existing knowledge in literature. 


\subsection{Research aim and contribution}

The aim of this paper is to investigate the nonlinear seismic performance of RC columns under unidirectional and bidirectional multiple excitations. To consider the cross-sectional geometry effect, a rectangular and a circular RC column with equal lateral stiffness have been selected. To capture different failure modes of RC columns under seismic excitation an advanced nonlinear fibre model is employed. The model simulates degradation of materials under cyclic loading, including inelastic buckling and low-cycle fatigue degradation of longitudinal reinforcement. A series of monotonic pushover and incremental dynamic analyses (IDAs), [46] are conducted on hypothetical rectangular and circular columns. Inclusive methodology, validation and detail of the model is available at Kashani et al. [47-50]; Afsar Dizaj et al. [51-52]. A dimensionless damage index, developed by Mergos et al. [53], has been implemented for quantification of different sources of damage including flexural, shear and bond-slip damage in the cantilever RC columns. Proposing a unique algorithm, in the current study, this damage index is further extended to be used in the seismic performance assessment of RC structures under bidirectional excitations. A successful example of using such damage index in seismic performance assessment of RC columns can be found in Afsar Dizaj et al. [54].

To investigate the impact of fatigue, multiple excitations including mainshock and aftershock have been considered. Ground motion records are carefully selected using conditional mean spectrum (CMS), [Baker, 55], to generate real as-recorded mainshock and aftershock (MSAS) sequences. CMS is intentionally implemented to consider the regional seismic hazard of the selected site. In this paper, the hypothetical columns are located in Los Angeles, US. Section 2 is dedicated to the description of the RC column model, followed by the description of the advanced damage index used in this study. The MSAS ground motion selection is explained in Section 4. Subsequently, the results and discussion regarding the impact of multiple uni- and bidirectional excitation are presented at the end of this paper in Section 5. Fig. 1 represents a flowchart summarising the framework for this study. The results/discussions are presented in three separate

sections: i) comparison between uni- and bidirectional loading using single excitation (i.e. mainshock from now called MS), ii) comparison between bidirectional loading using MS and multiple excitations (i.e, from now MSAS), and iii) evaluating the impact of uni- and bidirectional loading using MSAS sequences.

\section{Reinforced Concrete Model}

\subsection{Proposed RC columns}

To investigate the impact of bidirectional loading and the contribution of bar buckling, bond-slip and low-cycle fatigue, two RC columns with circular and rectangular cross-section are considered. The circular column is the test specimen 415 from Lehman et al. [4] available at PEER column database [56], which is used as a benchmark column. A hypothetical rectangular column with the same axial load ratio and material properties is designed. Both rectangular and circular RC columns are designed in a way to have relatively close lateral stiffness and consequently having an equal un-cracked fundamental period of vibration. The details of the RC columns are 
presented in Table 1 and shown in Fig. 2. The effective buckling length of vertical reinforcements (Leff) reported in Table 1 is calculated using the iterative procedure proposed by Dhakal-Maekawa [57]. In this method, tie stiffness and required stiffness to avoid buckling of longitudinal reinforcements are compared to find the buckling mode and buckling length accordingly. For further details on methodology, application and validation please refer to Kashani et al. [48] and Dhakal-Maekawa [57].

The proposed modelling technique has been implemented using OpenSees [58] to simulate the nonlinear dynamic behaviour of rectangular and circular RC columns under bidirectional loading. Each RC column is modelled using two force-based nonlinear fibre beam-column elements. The length of the first element at the bottom of the column is adjusted in a way that the integration length of the first integration point is equal to the effective length of the vertical reinforcement. The first element has three integration points (fibre sections) and the second element has five integration points. Both finite element models for rectangular and circular RC columns are capable to simulate bar buckling, low-cycle fatigue and bond-slippage (for validation please refer to Kashani et al. [47-50]). 

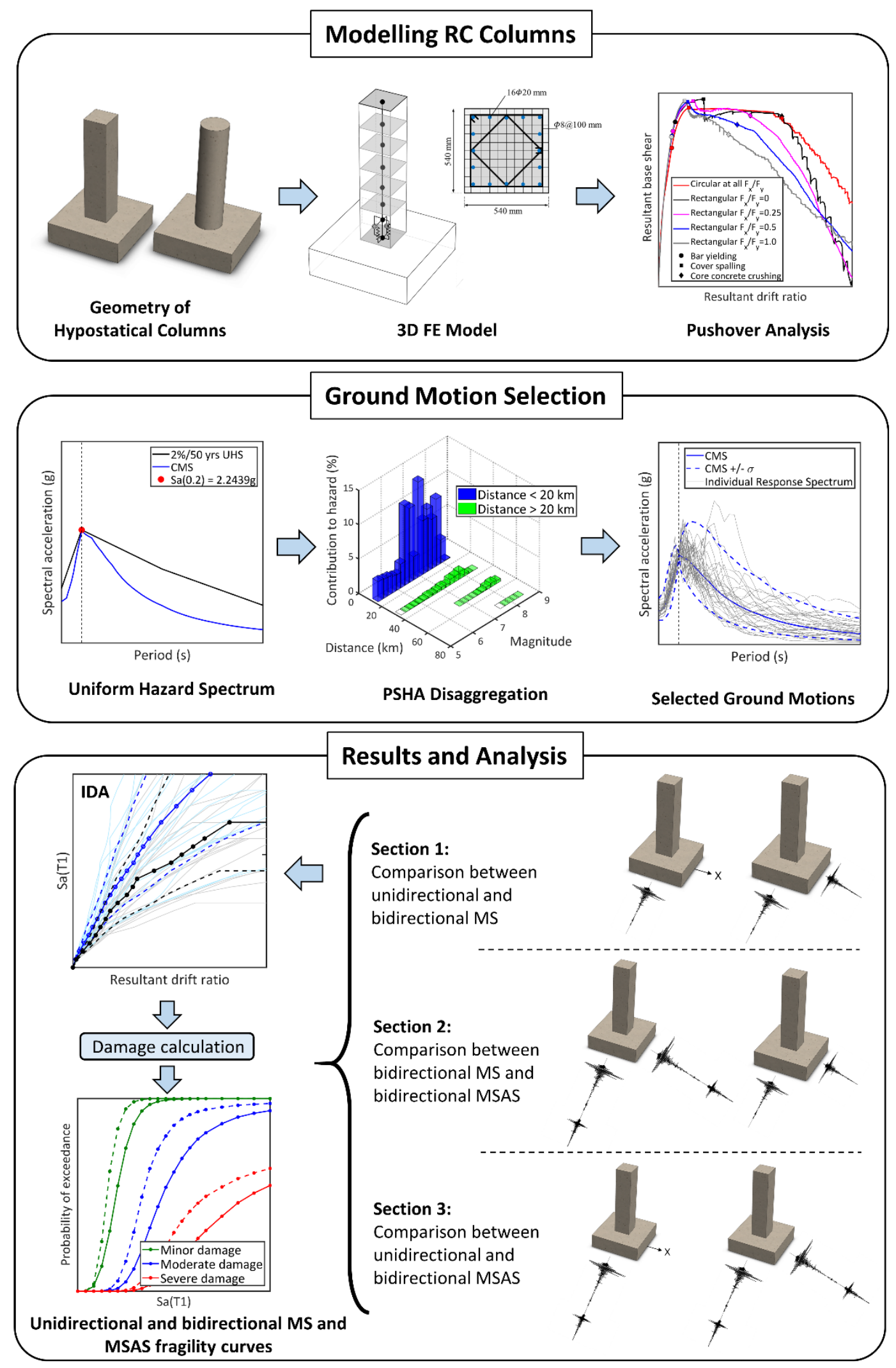

Fig. 1. Flowchart of the methodology for seismic performance assessment of circular and rectangular RC columns subjected to unidirectional and bidirectional MSAS sequences

\subsection{Description of the material models}

The implemented model in this paper is capable of simulating the nonlinear structural response of RC structures and capture damage starting from crack initiation at small deformation to structural instability at 
large deformation. To overcome the limitations of lumped plasticity models such as axial-flexural force interaction and to incorporate the concrete tensile strength and tension stiffening, fibre-based beam-column models are more popular, in particular under bidirectional loading. Generally, to simulate the cyclic response of reinforcing bars, the uniaxial material model based on Giuffre-Mengotto-Pinto [GMP, 59], is used. The material model is known as Steel02 in OpenSees which accounts for Bauschinger effects [60], but it does not consider the cyclic strength and stiffness degradation due to bar buckling and fatigue. To consider the impact of bar buckling, uniaxial Hysteretic material model available in OpenSees is used. The material model is calibrated based on a phenomenological material model of reinforcing bars previously developed by Kashani et al. [48] that simulate bar buckling. To capture the low-cycle fatigue degradation of reinforcing bars, the Fatigue material model available in OpenSees is wrapped to the Hysteretic material model. The uniaxial Fatigue model is based on Coffin-Manson [61] log-log relationships describing low cycle fatigue failure (i.e. Miner's Rule). The Fatigue material model does not change the stress-strain curve of the parent material; however, the stress of the parent steel material drops to zero if the fatigue damage index reaches to 1.0. The calibration of the Fatigue material constant is very important as it can considerably change the outcome of the simulation; therefore, the parameters for the Fatigue material model are taken from an experimental study conducted by Kashani et al. [62].

In this paper, the nonlinear behavior of confined and unconfined concrete for a rectangular column is modeled using uniaxial material Concrete02. As it is shown in Fig. 2, it has a parabolic curve up to the maximum concrete stress and a linear post-peak softening branch to a residual strength which his $20 \%$ of the maximum compressive strength. The influence of confinement on the stress-strain relationship of core concrete is modelled using the modified Kent-Park model [63]. In another study by Kashani et al. [50], it was found that Concrete04 is more suitable for circular columns. Concrete04 employs the Popovics model [64] with a linear loading and unloading degradation according to Karsan-Jirsa [65] and exponential decay for tensile strength. The effect of confinement on the compressive strength of the core concrete is considered using Mander's model [66].

\subsection{Bond-slip model}

The slippage of reinforcing bars between the RC column and footing due to strain penetration results in fixedend rotation which is known as one of the primary sources of damage. The result of an experimental study conducted by Hachem et al. [24] suggests that bar-slip can increase the ultimate displacement of an RC column by about $30 \%$ and affects the lateral stiffness. Including the bond-slip damage due to fixed-end rotation is essential to accurately predict the damage of RC columns under uni- and bidirectional loading. To do so, the stress-slip constitutive material model developed by Zhao et al. [67] is assigned to a zero-length section element at the base of each column. 
Table 1. Details of the hypothetical columns

\begin{tabular}{lccccccc}
\hline Cross section shape & $L(\mathrm{~mm})$ & $L / D$ & $L_{\text {eff }} / d$ & $\rho_{l}(\%)$ & $\rho_{s}(\%)$ & $N_{u} /\left(f_{c} A_{g}\right)$ & $T(\mathrm{~s})$ \\
\hline Rectangular & 2438.4 & 4 & 10 & 1.49 & 0.7 & 0.045 & 0.20 \\
\hline Circular & 2438.4 & 4.5 & 10 & 1.72 & 0.8 & 0.045 & 0.20 \\
\hline
\end{tabular}

Column height $(L)$, shear span to depth ratio $(L / D)$, the ratio of effective buckling length of longitudinal bar to its diameter $\left(L_{\text {eeff }} / d\right)$, the ratio of longitudinal bars $\left(\rho_{l}\right)$, the volumetric ratio of transverse reinforcements $\left(\rho_{s}\right)$, axial force ratio $\left(N_{u} / f_{c} A_{g}\right)$ and fundamental period of each column $(T)$.

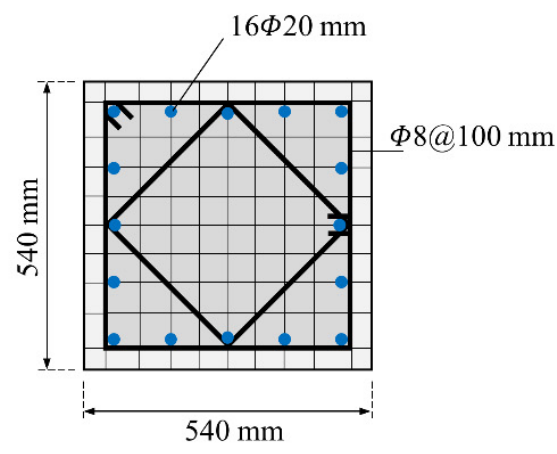

(a)

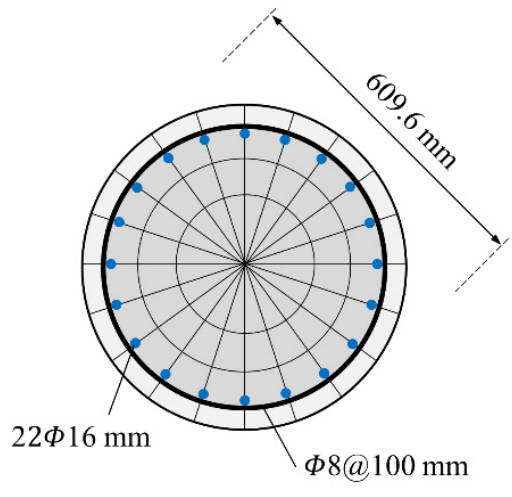

(b)

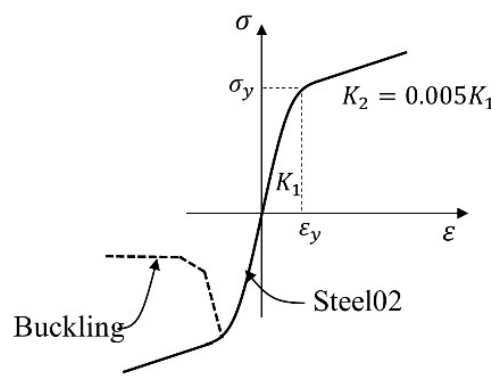

(c)

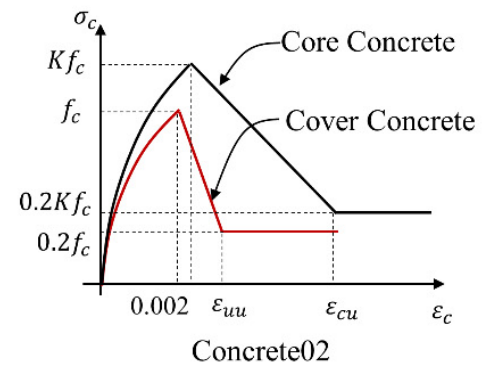

(d)

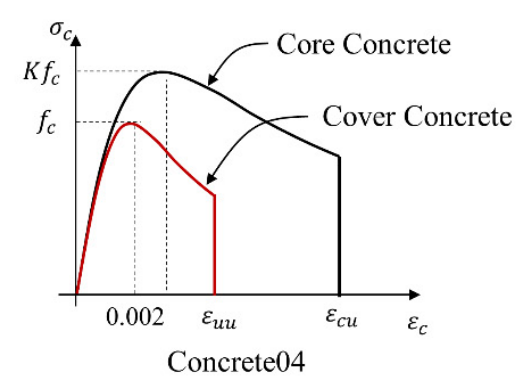

(e)

Fig. 2. Cross-sectional details of the hypothetical RC columns: (a) rectangular; (b) circular; (c) material model for reinforcements; (d) concrete material model for rectangular column; and (e) concrete material model for circular column

\subsection{Bidirectional pushover analysis}

Before running the time history simulations, a monotonic nonlinear bidirectional pushover analysis is performed for both the rectangular and circular columns. For each column, the resultant force-deformation output is calculated using the square root of sum of squares (i.e. SRSS) and presented in Fig. 3. The different states of damage such as bar yielding, concrete cover spalling and core concrete crushing are also mapped on the bidirectional pushover curves. The bidirectional loading conducted by changing the ratio of loading in $X$ direction over the corresponding ratio in the $Y$ direction (i.e. $\frac{F_{x}}{F_{y}}$ ), where $\frac{F_{x}}{F_{y}}=0$, implies unidirectional loading and $\frac{F_{x}}{F_{y}}=1$, refers to laterally pushing the columns with an angle of 45 degrees. The resultant pushover curves for the lateral load ratio of $\frac{F_{x}}{F_{y}}=0.25$ and 0.5 are also presented in Fig. 3. It is evident that for the circular section the direction or azimuth of loading does not change the resultant force-deformation curve. However, as also mentioned by Stewart et al. [11], azimuth-dependent structures such as rectangular RC columns are 
sensitive to the direction of loading. As the loading angle changes with respect to the principal axes, the forcedeformation curve decays and shows the highest sensitivity at the weakest axis (in this case at 45 degrees for a square column).
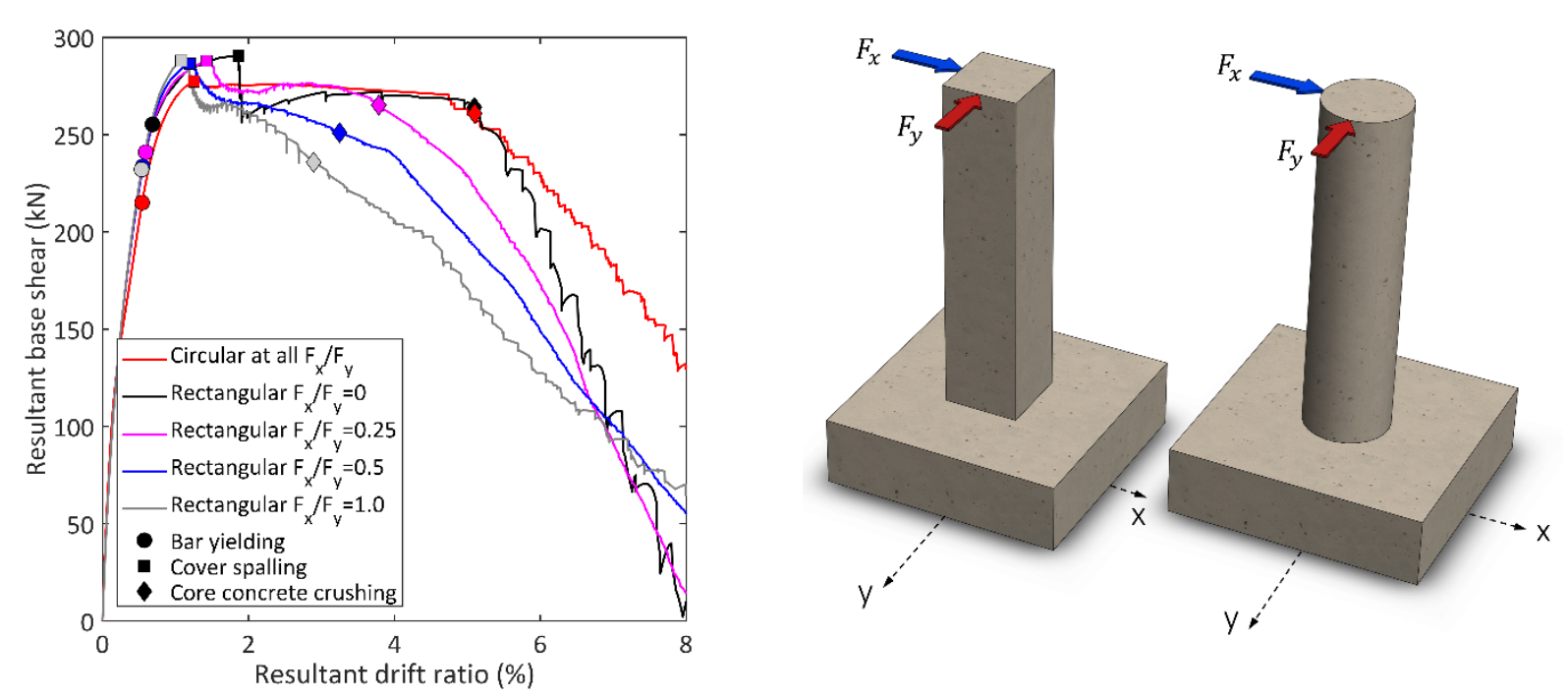

Fig. 3. Unidirectional and bidirectional pushover curves for rectangular and circular column

Fig. 3 shows that both the circular and rectangular columns exhibit bar yielding, concrete cover spalling and core concrete crushing under unidirectional and bidirectional loading. The damage conditions and corresponding drift ratios have been assigned based on uniaxial stress-strain response of fibres in the critical section of the RC columns (i.e. steel bar yielding strain, cover and core concrete crushing strains). However, the drift thresholds for each damage state decrease for a rectangular column by increasing the bidirectional load ratio from 0 to 1 . For example, the core concrete crushing for rectangular RC column under unidirectional loading starts from drift ratio of 5\%, while for the bidirectional pushover with a load direction of 45 degrees, the core concrete crushing initiates at approximately $3 \%$ resultant drift ratio, which shows a $50 \%$ reduction.

\section{Description of the local damage indices}

Damage indices are classified as cumulative and non-cumulative. Noncumulative damage indices relate the state of damage to the maximum response of the structure and do not consider the cyclic loading effects, such as inter-story drift ratio [68]. On the other hand, cumulative indices account for cyclic loading history effects on damage states of structures. Selecting a damage index is critical as it can significantly influence the outcome of seismic performance assessment of RC structures. A great review and suggestions regarding damage indices are provided by [68-70]. Different authors have investigated and used cumulative damage indices such as Park and Ang [71] to quantify damage for RC structures. Rodrigues et al. [15] explored seven damage indices based on different combinations of resultant maximum displacement, equivalent resultant yielding force and the sum of dissipated energy for RC columns under bidirectional loading. They found that a modified Park and Ang damage index that employs peak resultant yielding force and resultant displacement combined with the sum of dissipated energy in both directions predicts the damage of RC columns under bidirectional loading more realistically. 
Considering that the main sources of damage for RC columns under bidirectional loading are cover concrete spalling, core concrete crushing, bar buckling, bar fracture, bond-slip and shear, the damage index in this paper is based on a damage index that was proposed by Mergos et al. [53]. The selected damage index is a combined damage index developed for seismic assessments of RC structures which incorporates the contribution of all deformation mechanisms including flexural, shear and slippage of reinforcements. The equation for the damage index is presented in Eq. (1):

$$
\lambda_{t o t}=1-\left(1-\left(\frac{\varphi_{\max }}{\varphi_{u}}\right)^{1.35}\right) \cdot\left(1-\left(\frac{\gamma_{\max }}{\gamma_{u}}\right)^{0.8}\right) \cdot\left(1-\left(\frac{\theta_{s l, m a x}}{\theta_{u b, s l}}\right)^{0.95}\right)
$$

where $\lambda_{\text {tot }}$ is the total damage index, $\varphi_{\max }, \gamma_{\max }, \theta_{s l, \max }$ are maximum curvature, maximum shear and maximum fixed-end rotation caused by slippage of reinforcement, respectively. Finally, $\varphi_{u}, \gamma_{u}$ and $\theta_{u b, s l}$ present the ultimate values of deformation capacities based on the monotonic pushover analysis [53]. The advantage of this damage index is that if any of each sub-damage indices reaches to zero, subsequently the total damage index become 1, indicating the failure of the structure. Each damage state, the physical definition and range of $\lambda_{t o t}$ is presented in Table 2. Further details are available in [53].

Table 2. Damage limit states, definition and threshold for flexural, shear and bond-slip damage [53]

\begin{tabular}{|c|c|c|c|c|}
\hline Damage level & Flexural damage & Shear damage & Bond damage & $\begin{array}{c}\text { Damage } \\
\text { index }\left(\lambda_{\text {tot }}\right)\end{array}$ \\
\hline Minor & $\begin{array}{l}\text { Flexural cracks }(<2 \mathrm{~mm}) \\
\text { Limited yielding } \\
\text { No spalling }\end{array}$ & $\begin{array}{l}\text { Hairline minor shear } \\
\text { cracks }(<0.5 \mathrm{~mm})\end{array}$ & $\begin{array}{l}\text { Fixed-end cracks (<2 mm). } \\
\text { Hairline-visible bond cracks in } \\
\text { parts of the lap splices }\end{array}$ & $0.0-0.20$ \\
\hline Moderate & Spalling of cover concrete & $\begin{array}{l}\text { Moderate shear } \\
\text { cracking (>0.5 mm) }\end{array}$ & $\begin{array}{l}\text { Fixed-end cracks (>2 mm). } \\
\text { Moderate bond cracking in } \\
\text { parts of the lap splices }\end{array}$ & $0.20-0.50$ \\
\hline Severe & $\begin{array}{l}\text { Rebar Buckling, core concrete } \\
\text { disintegration, fracture of tensile } \\
\text { reinforcement, yielding or } \\
\text { fracture of transverse } \\
\text { reinforcement because } \\
\text { of core expansion }\end{array}$ & $\begin{array}{l}\text { Sever shear cracking } \\
\text { (> 1mm), stirrup } \\
\text { yielding or fracture }\end{array}$ & $\begin{array}{l}\text { Major fixed-end cracks indicating } \\
\text { reinforcement pullout. Severe bond } \\
\text { cracking along the full length of the } \\
\text { lap splices. Spalling of cover } \\
\text { surrounding lap-spliced bars }\end{array}$ & $0.50-1.00$ \\
\hline
\end{tabular}

Being inspired by the modified Park and Ang damage index that Rodrigues et al. [15]; Roy et al. [7273] used, in this paper, the damage index proposed by Mergos et al. [53] has been modified to include the bidirectional loading. In particular, instead of having a singular value for ultimate curvature which is only acceptable under unidirectional loading, the ultimate curvature is calculated for each angle of peak resultant deformation as it is presented in Fig. 4(a). For instance, the rectangular RC column under unidirectional loading parallel to principle axes in $X$ and $Y$ direction shows the highest value for ultimate curvature $\left(\varphi_{u x}, \varphi_{u y}\right)$, however, by changing the angle of loading (i.e. the ratio of $\frac{F_{x}}{F_{y}}$ as shown in Fig. 3 ) the ultimate curvature in both directions decays having the lowest magnitude at 45 degrees (i.e., $\frac{F_{x}}{F_{y}}=1$ ). It is evident that the circular $\mathrm{RC}$ section does not have a weak axis and the ultimate curvature is independent of the peak deformation angle. 
Similarly, the ultimate fixed-end rotation is dependent on the angle of peak deformation. For example, under unidirectional loading, while the ultimate fixed-end rotation in the $\mathrm{X}$ direction $\theta_{u x}$ is maximum, the fixed-end rotation of the orthogonal axis $\theta_{u y}$ is zero. By changing the angle of loading or the ratio of forces in $X$ and $Y$ direction in the pushover analysis, both directions participate in the damage due to bar slippage. Comparing the fixed-end rotation for circular and rectangular RC columns, it can be seen that the rectangular column has slightly better capacity/resistance for fixed-end rotation under bidirectional pushover analysis, while its ultimate curvature is hampered in the weak axis at 45 degrees. The ultimate shear capacity $\left(\gamma_{u}\right)$ under bidirectional loading is also presented in Fig 4(c) for both cross-section. Similar to ultimate curvature the ultimate shear deformation in the circular section is independent of the direction, while the rectangular section has the highest shear capacity at 45 degrees as both horizontal and vertical legs of the transverse reinforcement participate in the shear capacity. In this study as the columns are ductile and total response is flexural dominant, the shear deformation is considered in the elastic region and the interaction between flexure and shear backbone curve is omitted. For non-ductile RC column, the relevant formulation for ultimate shear deformation can be found in Mergos et al [74]. This assumption does not affect the accuracy of results, as the RC columns in this study are ductile and having a flexural dominant response. In case of non-ductile RC columns, plastic shear deformation is required to be considered by using the model proposed by Mergos et al. [74]; Sezen et al. [75,76]; Sae Long et al. [77].
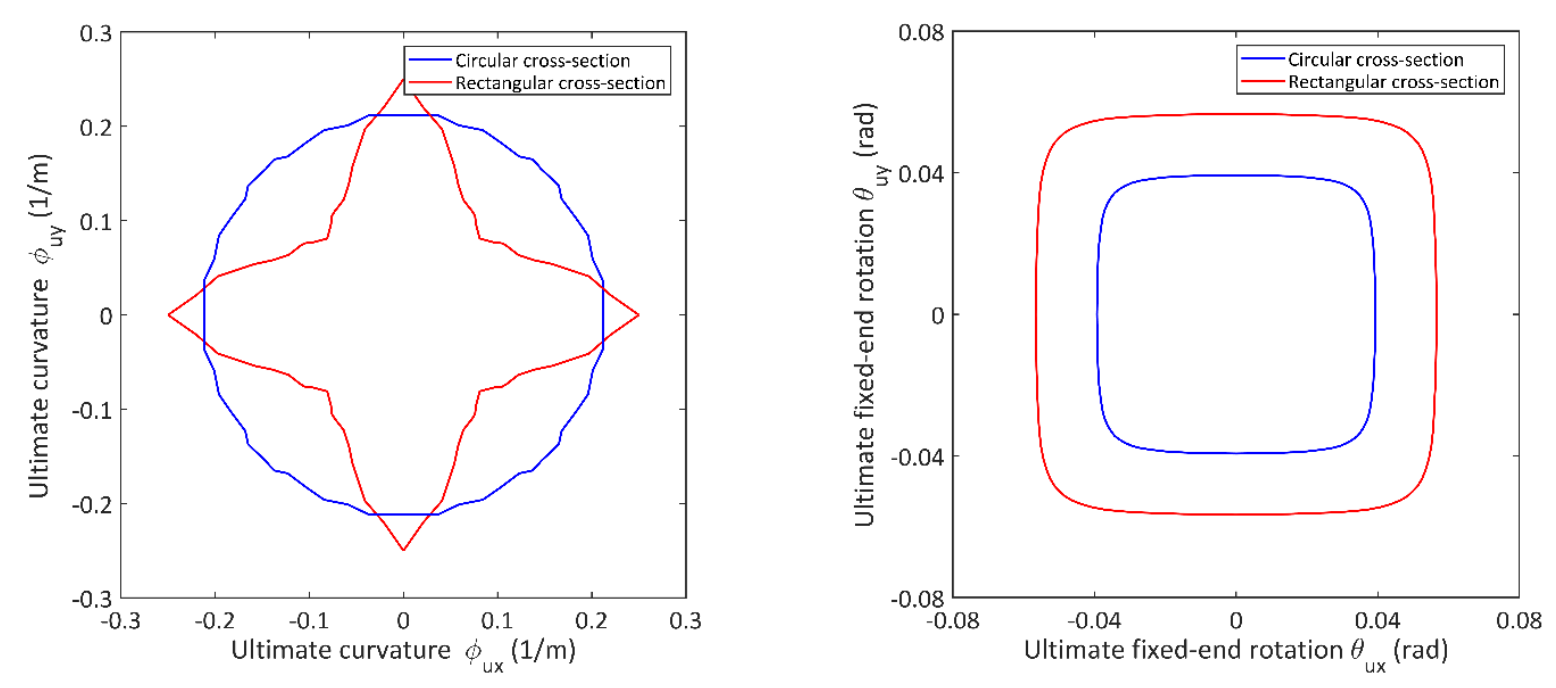
(a)

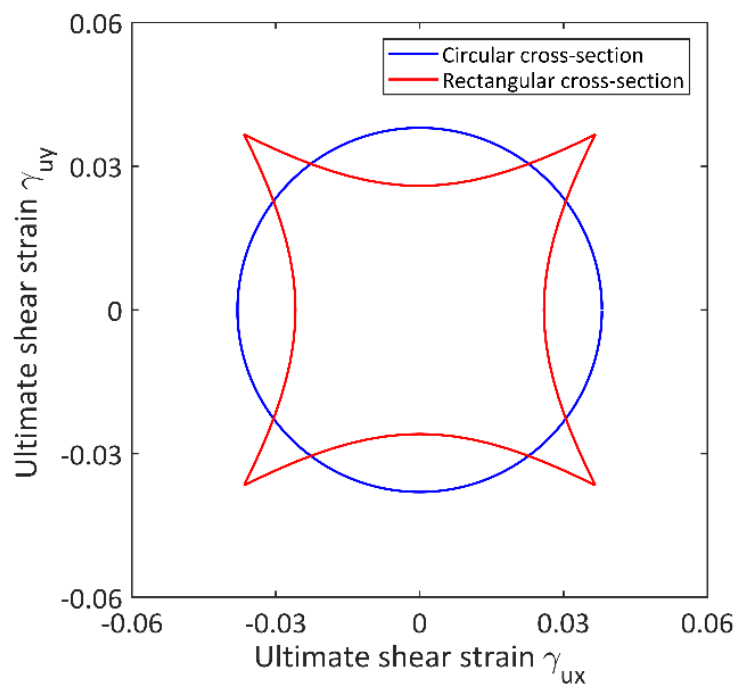

(c)

(b)

Fig. 4. Deformation capacity of the circular and rectangular column under bidirectional pushover analysis, (a) ultimate curvature $\left(\varphi_{u}\right),(b)$ ultimate fixed-end rotation $\left(\theta_{u}\right)$ c) ultimate shear strain $\left(\gamma_{-} u\right)$

Having the ultimate capacities for bidirectional bending, shear and slippage, the next step is to calculate the maximum curvature $\left(\varphi_{\max }\right)$, maximum fixed-end rotation $\left(\theta_{s l, \max }\right)$ and maximum shear $\left(\gamma_{\max }\right)$ in each bidirectional time history analysis. To run the dynamic analysis under bidirectional excitation, both components of each selected ground motion record are simultaneously applied along with two principal axes; then, drifts in two orthogonal directions are recorded over the entire time history. The maximum response in each direction is called directional peak $[15,72-73]$. Directional peaks ( $\Delta_{x}$ and $\Delta_{y}$ ) may occur at different instants and hence to evaluate the resultant peak $\left(\Delta_{\text {res }}\right)$, the responses in two orthogonal directions are combined using the SRSS method through the entire history and the resultant peak is taken as maximum drift under bidirectional excitation. Having the $\mathrm{X}$ and $\mathrm{Y}$ components of the resultant peak response (i.e. $\Delta_{\text {res }}$ ), the corresponding resultant peak angle can be calculated as $\psi_{\text {res }}=\tan ^{-1}\left(\frac{\Delta_{y, r e s}}{\Delta_{x, \text { res }}}\right)$. Accordingly, the peak bidirectional curvature $\varphi_{\max , \text { res }}$, peak bidirectional fixed-end rotation $\theta_{\text {max,res }}$ and peak bidirectional shear strain $\gamma_{\text {max }}$,res can be calculated. An algorithm in MATLAB finds all above-mentioned parameters and calculates the peak resultant angle (i.e. $\psi_{\text {res }}$ ). The corresponding ultimate values presented in Fig. 4 are extracted with respect to peak resultant angle; thus, the sub-damage ratios are calculated consequently. Fig. 5, demonstrate the framework to calculate the damage index under bidirectional loading used in this paper. 


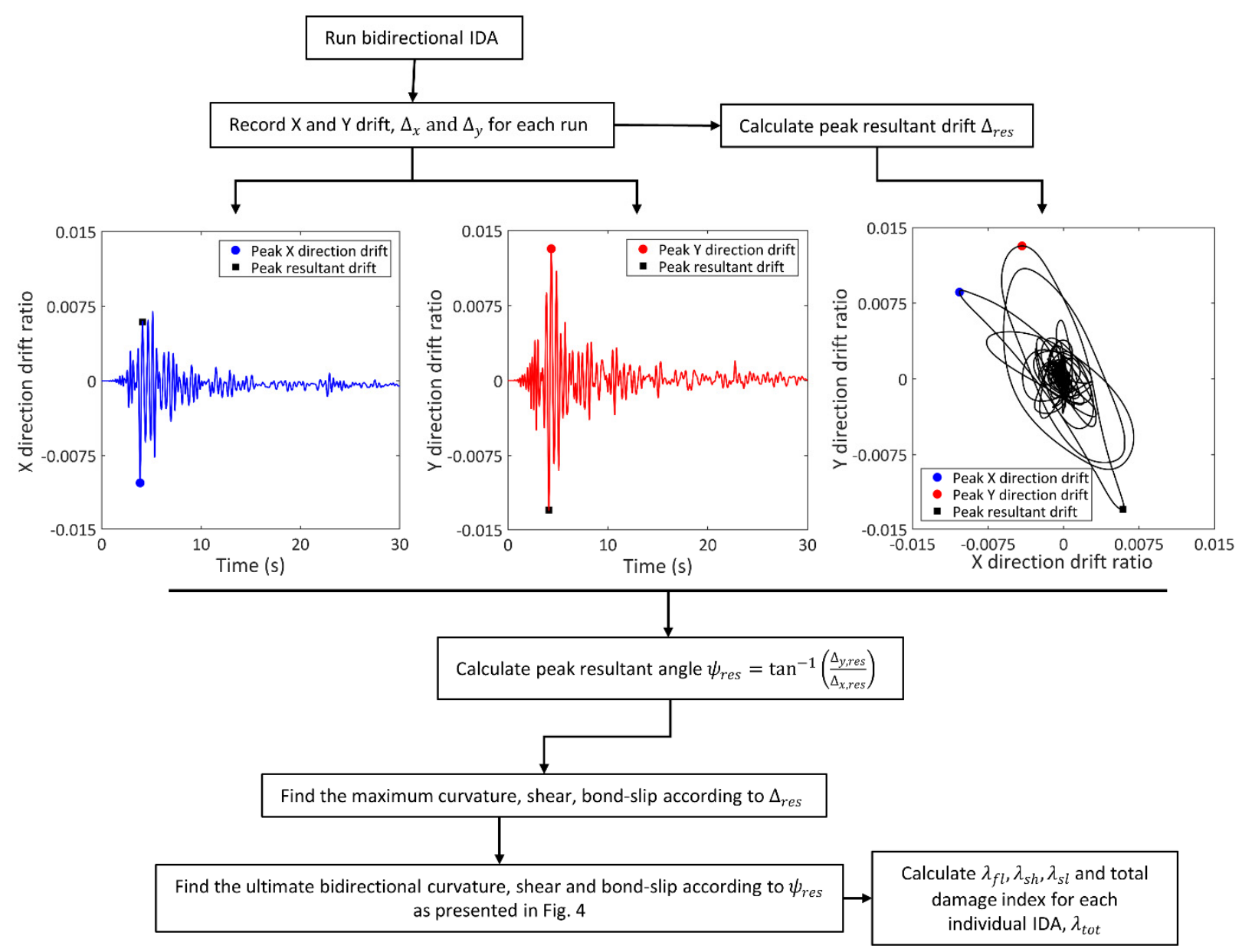

Fig. 5. Overview of the proposed algorithm to calculate damage index for RC columns under bidirectional loading

\section{Ground motion selection}

To incorporate the seismic hazard and reduce the uncertainty in ground motion records, a ground motion selection based on CMS [55], has been used in this study. CMS provides the expected (i.e., mean) response spectrum, conditioned on the occurrence of a target spectral acceleration value at the period of interest (i.e. $T_{1}$ ). In this paper, it is assumed that the proposed columns are located in a typical urban site in Los Angeles, US, (latitude/longitude $=34.0522^{\circ} \mathrm{N} / 118.2437^{\circ} \mathrm{W}$ ). The soil is assumed to be of the NEHRP soil D classification $(V s=259 \mathrm{~m} / \mathrm{s})$. The uniform hazard spectrum with the $2 \%$ probability of exceedance in 50 years is presented in Fig. 6a. The information in this section is publicly available from the probabilistic seismic hazard analysis (PSHA) information provided by USGS (https://www.usgs.gov). Considering the prior knowledge about the fundamental vibration period of the columns to be 0.2 second, the spectral acceleration at the period of interests $\mathrm{Sa}\left(\mathrm{T}_{1}\right)$ is $2.24 \mathrm{~g}$. Another useful information provided by USGS is the disaggregation information for any specific site in the US. Fig. $6 b$ shows the distribution of magnitudes, distance and their contribution to the site hazard for the specific location in Los Angeles, US. In this paper to be aligned with the tectonics of the site, only shallow crustal ground motions having a distance of less than $40 \mathrm{~km}$ are considered. Using the average 
values of distance and magnitude suggested by the USGS, a single target response spectrum (CMS) is constructed to select the records suitable for this study. Fig. 6a also presents the ground motion prediction equations (GMPEs) associated with $M=6.6, R=10 \mathrm{~km}$, and $\varepsilon=2.8$ and the average predicted median spectrum. As suggested by USGS, five GMPEs including Abrahamson et al. [78]; Chiou et al. [79]; Campbell et al. [80]; Boore at al. [81] with a weight factor of 0.22 and Idriss [82] with a weight factor of 0.12 are used.

To have a sufficient number of records for IDA analysis, it is inevitable to use ground motion data from other seismic regions. The MSAS sequences in this paper are selected from the PEER-NGA database that was previously assembled from worldwide shallow crustal earthquakes by Goda and Taylor [83] to investigate the impact of real MSAS of single-degree-of-freedom (SDOF) systems. It is important to clarify that the records are real as-recorded ground motions and no artificialness except the amplitude scaling in imposed on them (i.e. no randomised or back-to-back records).

The MS and AS are distinguished by the magnitude of the ground motions, the record with the highest magnitude is called mainshock and any following ground motion is considered as an aftershock. The selection of desired MSAS is conducted from the 172 sequences (each sequence consists of two horizontal components) available from the PEER-NGA database. After having the target CMS for the specific location, the next step is to scale up or down the geometric mean of both horizontal components to match the $\mathrm{Sa}\left(\mathrm{T}_{1}\right)$ which is presented in Fig. 6c. As it was mentioned the only artificialness is the amplitude scaling, therefore the frequency content and duration of records are kept unchanged. The records that match the target spectrum can be selected. The selection is based on the error calculate between each record and the target CMS spectrum. As suggested by Baker et al. [84], the period range from $0.2 \mathrm{~T}_{1}$ to $2.0 \mathrm{~T}_{1}(0.04-0.4 \mathrm{~s})$ is selected in this study for record selection. This is the period range that structural response is the most sensitive to the input excitation. The total number of selected records is 31 as presented in Fig. $6 \mathrm{~d}$ and their detailed information is summarised in Table 3. It is worth mentioning that in this study only one major aftershock record is selected and the impact of several aftershocks and their contribution to damage, in particular, the low-cycle fatigue is granted in another study. After having the selected real MSAS records that reflect the seismic hazard level in Los Angeles, US, IDA can be conducted to calculate the capacity of the RC columns under uni- and bidirectional multiple MSAS records. 


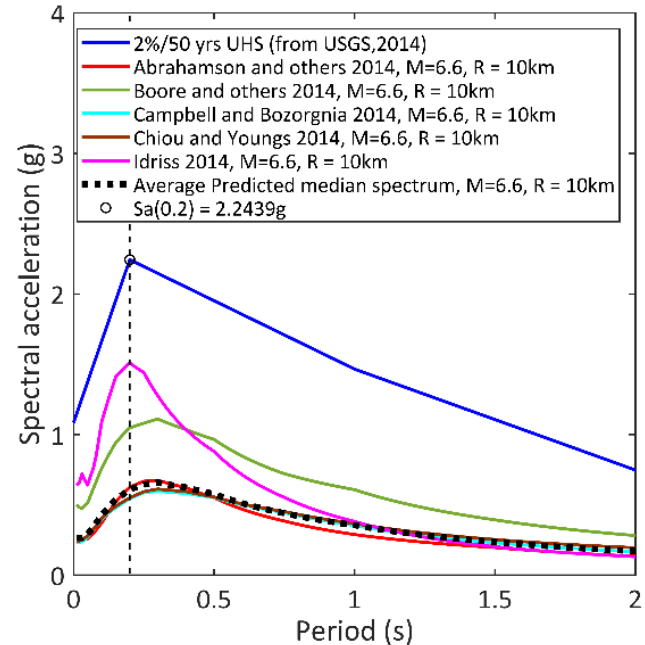

(a)

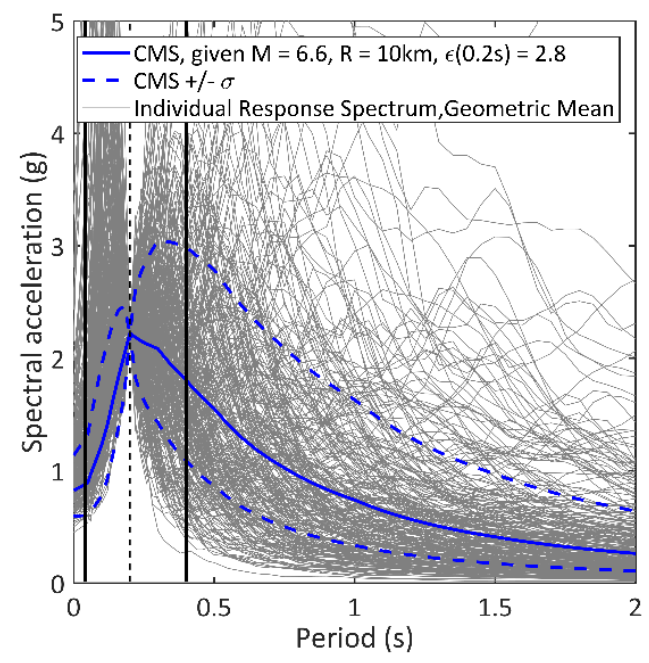

(c)

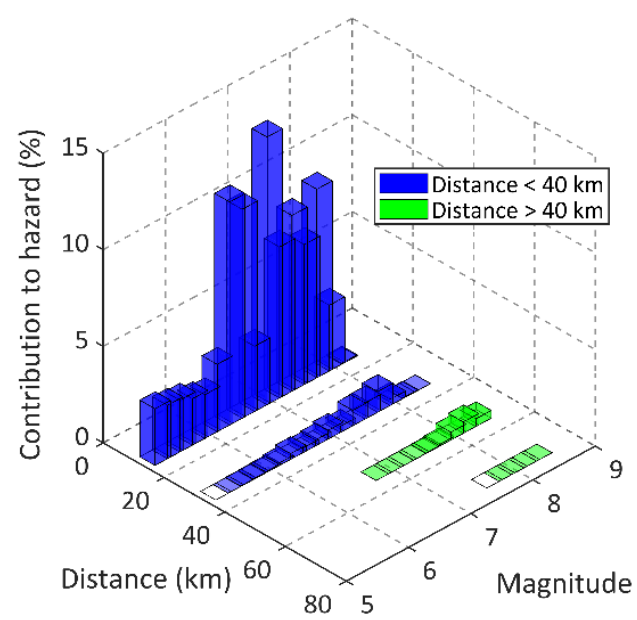

(b)

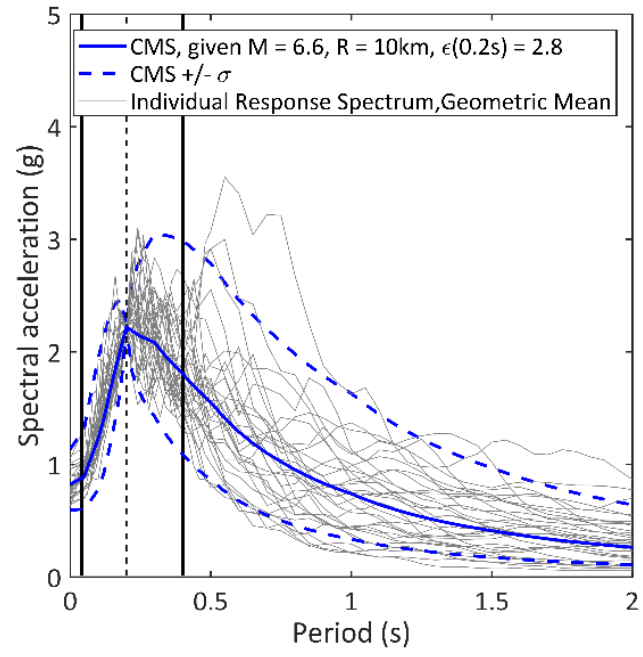

(d)

Fig. 6. MSAS record selection, (a) UHS for Los Angles with GMPE, (b) disaggregation information from USGS, (c) conditional mean spectrum (CMS) with a geometric mean of all individual real MS records, (d) selected MS records for the specific structure and location.

Table 3. Summary of the constructed real mainshock-aftershock ground motion sequences

\begin{tabular}{lclllll}
\hline Event name & Station ID & Magnitude & Distance $(\mathrm{km})$ & $\mathrm{V}_{\mathrm{s} 30}(\mathrm{~m} / \mathrm{s})$ & $\mathrm{PGA}^{*}(\mathrm{~g})$ & $\mathrm{PGV}(\mathrm{cm} / \mathrm{s})$ \\
\hline Managua-01 \& 02 & 199 & $6.24,5.2$ & $4.06,7.57$ & 288.77 & $0.394,0.287$ & $25.39,26.85$
\end{tabular}




\begin{tabular}{|c|c|c|c|c|c|c|}
\hline Fruili, Italy-02 \& 03 & 257 & $5.5,5.91$ & $15.08,11.03$ & 338.6 & $0.046,0.108$ & $4.88,10.8$ \\
\hline Imperial Valley-06 \& 07 & 119 & $6.53,5.01$ & $7.05,14.43$ & 208.91 & $0.401,0.204$ & $69.89,9.23$ \\
\hline Imperial Valley-06 \& 07 & 211 & $6.53,5.01$ & $7.65,12.32$ & 202.89 & $0.234,0.169$ & $47.47,11.3$ \\
\hline Irpinia, Italy-01 \& 02 & 621 & $6.9,6.2$ & $17.64,8.83$ & 600 & $0.153,0.177$ & $17.52,24.32$ \\
\hline Irpinia, Italy-01 \& 02 & 935 & $6.9,6.2$ & $10.84,20.39$ & 1000 & $0.295,0.076$ & $43.74,4.42$ \\
\hline Coalinga, 02 \& 04 & 175 & $5.09,5.18$ & $12.44,12.62$ & 376.073 & $0.138,0.154$ & $5.15,5.84$ \\
\hline Coalinga-02 \& 03 & 176 & $5.09,5.38$ & $17.76,15.75$ & 352.2 & $0.087,0.174$ & $3.89,8.88$ \\
\hline Coalinga-04 \& 05 & 183 & $5.18,5.77$ & $10.35,9.52$ & 376.073 & $0.186,0.879$ & $9.85,38.53$ \\
\hline Coalinga-02 \& 03 & 412 & $5.09,5.38$ & $16.71,14.77$ & 338.539 & $0.12,0.055$ & $5.51,5.27$ \\
\hline Chalfant Valley-01 \& 02 & 430 & $5.77,6.19$ & $24.33,21.92$ & 271.441 & $0.052,0.19$ & $2.63,14.58$ \\
\hline Chalfant Valley-01 \& 02 & 432 & $5.77,6.19$ & $23.47,17.17$ & 271.441 & $0.106,0.21$ & $8.65,20.52$ \\
\hline Chalfant Valley-01 \& 02 & 438 & $5.77,6.19$ & $6.39,7.58$ & 271.441 & $0.243,0.418$ & $20.01,41.14$ \\
\hline Northridge-01 \& 06 & 315 & $6.69,5.28$ & $8.66,13.51$ & 297.71 & $0.321,0.125$ & $30.53,5.49$ \\
\hline Northridge-01 \& 06 & 318 & $6.69,5.28$ & $29.88,29.89$ & 297.07 & $0.205,0.056$ & $16.42,2.44$ \\
\hline Northridge-01 \& 02 & 324 & $6.69,6.05$ & $5.92,14.34$ & 269.14 & $0.672,0.041$ & $83.75,2.25$ \\
\hline Northridge-01 \& 06 & 333 & $6.69,5.28$ & $23.41,23.44$ & 277.98 & $0.231,0.123$ & $23.75,5.37$ \\
\hline Kocaeli \& Duzce, Turkey & 709 & $7.51,7.14$ & $15.37,6.58$ & 276 & $0.323,0.428$ & $54.08,69.57$ \\
\hline Chi-Chi, Taiwan-01 \& 02 & 653 & $7.62,5.9$ & $16.06,58$ & 233.14 & $0.257,0.093$ & $38.37,4.68$ \\
\hline Chi-Chi, Taiwan-01 \& 04 & 685 & $7.62,6.2$ & $28.91,38.35$ & 417.56 & $0.133,0.08$ & $11.48,5.87$ \\
\hline Chi-Chi, Taiwan-01 \& 06 & 1017 & $7.62,6.3$ & $26.32,63.12$ & 272.6 & $0.212,0.053$ & $43,3.99$ \\
\hline Chi-Chi, Taiwan-01 \& 05 & 1022 & $7.62,6.2$ & $3.78,49.58$ & 487.27 & $0.272,0.062$ & $53.87,2.92$ \\
\hline Chi-Chi, Taiwan-01 \& 05 & 1023 & $7.62,6.2$ & $9.51,54.13$ & 272.6 & $0.136,0.137$ & $39.25,4.64$ \\
\hline Chi-Chi, Taiwan-01 \& 05 & 1024 & $7.62,6.2$ & $7.66,51.32$ & 272.6 & $0.213,0.126$ & $43.24,4.46$ \\
\hline Chi-Chi, Taiwan-01 \& 05 & 1035 & $7.62,6.2$ & $16.62,68.07$ & 272.6 & $0.118,0.042$ & $47.76,3.02$ \\
\hline Chi-Chi, Taiwan-01 \& 02 & 1042 & $7.62,5.9$ & $13.46,7.68$ & 549.43 & $0.443,0.153$ & $54.14,9.91$ \\
\hline Chi-Chi, Taiwan-01 \& 02 & 1046 & $7.62,5.9$ & $10.97,10.41$ & 363.99 & $0.536,0.319$ & $50.34,11.89$ \\
\hline Chi-Chi, Taiwan-01 \& 05 & 1060 & $7.62,6.2$ & $2.13,52.98$ & 272.6 & $0.224,0.05$ & $57.12,2.19$ \\
\hline Chi-Chi, Taiwan-01 \& 02 & 1074 & $7.62,5.9$ & $25.44,57.6$ & 215 & $0.131,0.04$ & $58.49,4.62$ \\
\hline Chi-Chi, Taiwan-01 \& 03 & 1079 & $7.62,6.2$ & $14.93,31.79$ & 272.6 & $0.149,0.065$ & $40.25,10.98$ \\
\hline Chi-Chi, Taiwan-01 \& 02 & 1077 & $7.62,5.9$ & $7.41,36.8$ & 459.34 & $0.23,0.041$ & $47.87,3.98$ \\
\hline
\end{tabular}

*The values of PGA and PGV listed in this table are taken from the PEER-NGA database flat file

\section{Results and discussion}

In this section, the results for circular and rectangular RC columns under uni- and bidirectional multiple excitations are discussed. In particular, the IDA median curves, fatigue damage index and the fragility curves are presented. The fatigue damage index is collected from the material recorders (Section 2) and presented 
here to clarify the impact of low-cycle fatigue. The fragility curves are calculated using the modified damage index [53] that combines flexural, shear and bond-slip damage.

\subsection{Investigating the impact of bidirectional loading using single excitation (1D-2D MS)}

Reviewing the literature and current practice, the seismic performance assessment and design of RC structures is mainly achieved by 2D models, hence neglecting the three-dimensional characteristic of ground motions. It has been revealed experimentally that bidirectional loading tends to reduce the ultimate stiffness/strength of RC columns, and in the rectangular column, this reduction can be approximately from $50 \%$ to $75 \%$ [15]. This amplification in damage under bidirectional loading can significantly reduce the ultimate capacity of the columns and ultimately endanger the integrity of RC structures. However, the combined impact of bidirectional excision and random characteristics of ground motions has not been explored thoroughly.

This section presents the result of extensive investigation regarding the circular and rectangular RC columns under uni- and bidirectional loading. The IDA simulations were performed using the 31 selected MS records, therefore the unidirectional IDA simulation has been conducted using 62 individual records. The summarised IDA curves are given in Fig. 7 ( $a$ and b). It is evident that for lower drift levels less than 1\%, the difference between uni- and bidirectional excitation is minimal. However, for the circular and rectangular RC columns, the median IDA curve shows a significant reduction in capacity for columns under bidirectional loading. Fig. 7(c and d) presents the distribution of low-cycle fatigue damage index for the RC columns under uni- and bidirectional excitations. The results belong to the maximum fatigue damage index of the quadrant and corner reinforcements for the rectangular and circular cross-section, respectively. Generally, the bidirectional loading increases the median fatigue damage index. However, under unidirectional loading, the steel reinforcement in the circular column shows a higher value of the median fatigue damage index in comparison with corner bars at the rectangular section. This can be justified considering that the quadrant reinforcements in circular section go under higher amplitude variation of cycle strain. On the other hand, reflecting on bidirectional loading, the corner bars in the rectangular cross-section show a significant increase of fatigue damage index. The same observation has been reported by Hachem et al. [24] and Sengupta et al. [30] about the impact of bidirectional loading and the important contribution of low-cycle fatigue for RC columns. On a related matter, the same observation was reported by Zeris et al. [28]. They found that under bidirectional loading, high strains may be induced at the critical section level, particularly at the corner reinforcements.

To fully understand the damage mechanism of circular and rectangular sections under bidirectional loading, it is essential to look at the material response of concrete and steel fibres. Fig. 8 shows the crosssections and the selected longitudinal reinforcements and their associated notation (i.e. East, West, North, South for circular section and NW, NE, SW and SE for rectangular column). As an example, the response of the rectangular and circular RC columns under a sample MS excitation scaled at $\mathrm{Sa}\left(\mathrm{T}_{1}\right)=1 \mathrm{~g}$ have been examined. In particular, the bidirectional drift, drift time-history, stress-strain response of longitudinal reinforcement and 
core concrete adjacent to the selected longitudinal reinforcement and the fatigue damage index time-history for uni- and bidirectional excitations are presented in Figs. 9 and 10 for rectangular and circular columns, respectively.

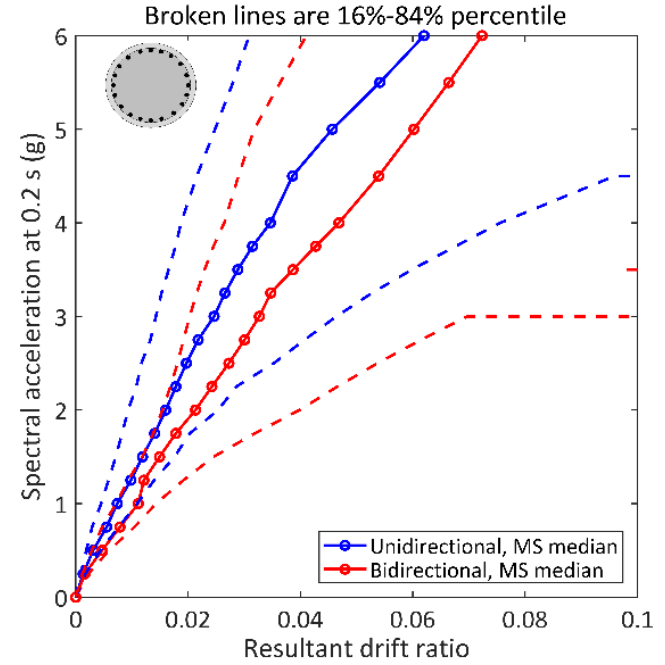

(a)

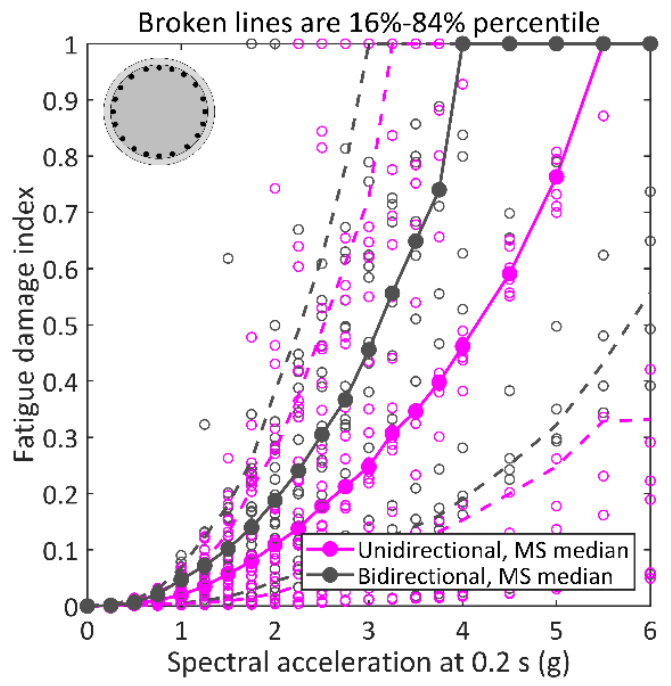

(c)

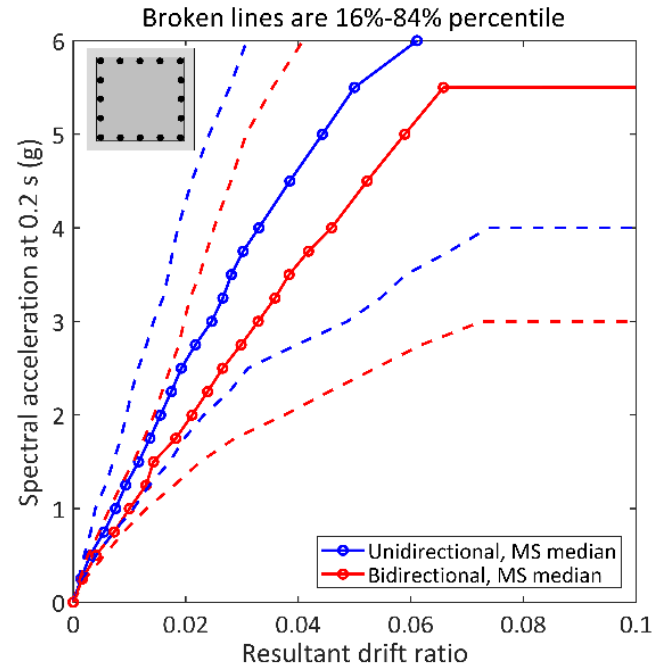

(b)

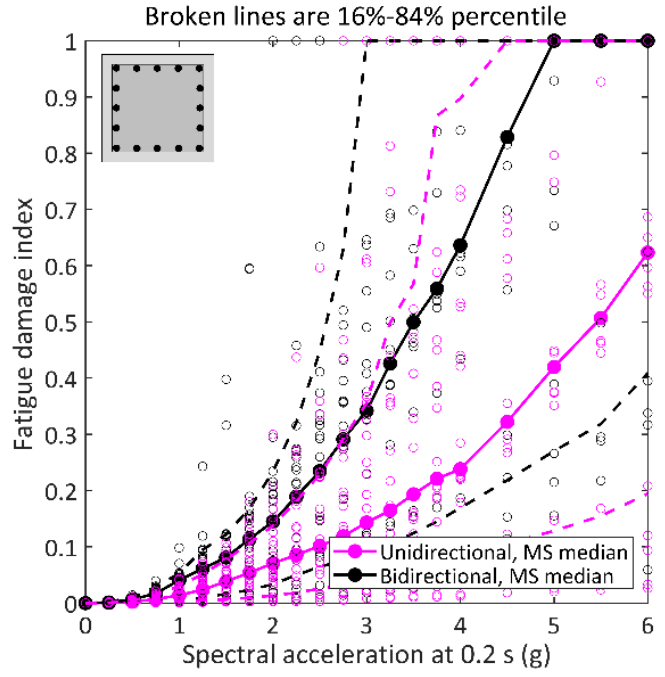

(d)

Fig. 7. Impact of unidirectional and bidirectional MS loading on the structural response of circular and rectangular columns, ( $a$ and $b$ ) median IDA curves, ( $b$ and $c$ ) fatigue damage index under mainshock excitation

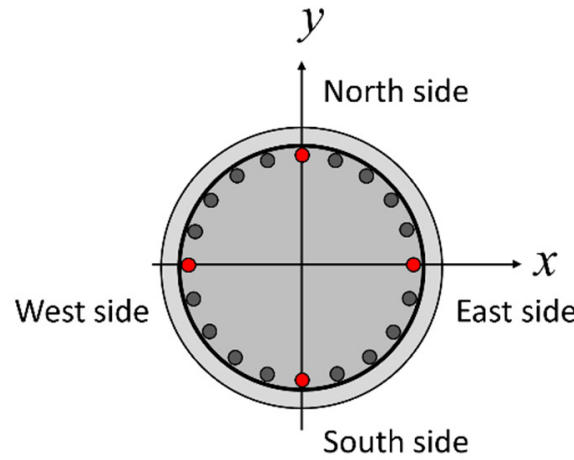

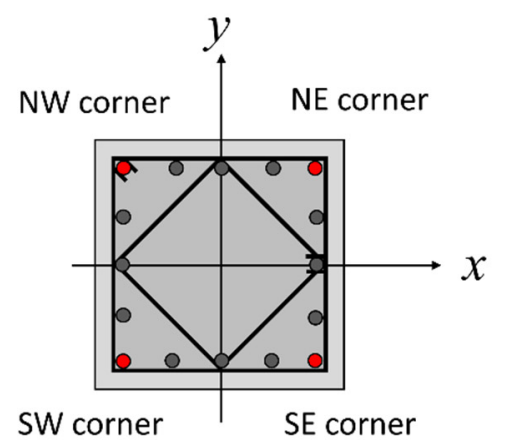

SW corner 
Fig. 8. Cross-section of circular and rectangular RC column and the location of the selected longitudinal reinforcements to demonstrate material responses

The impact of bidirectional loading can be seen by comparing the stress-strain response of steel and concrete, and the fatigue damage index. For instance, Fig. 9(a) presents the drift in $\mathrm{X}$ and $\mathrm{Y}$ directions. The red and blue markers highlight the maximum directional drift, while the black circular marker shows the maximum resultant drift. The stress-strain curves for two corner longitudinal reinforcements with the maximum response in compression and tension are presented in Fig. 9(b). The SW-corner reinforcement is at the highest compression corresponding to the peak resultant drift. It can be interpreted that the SW-corner bar is at the post-buckling stage followed by a premature core concrete crushing, while the NW-corner reinforcement is under the maximum tensile stress. The response of the concrete fibres adjacent to the longitudinal reinforcements is given in Fig. 9(c). Similarly, the South-West corner is under the highest compression while the North-West failed under tension and stress has dropped to zero. The important observation is presented in Fig. 9(d), as the material responses reach to the highest values, the fatigue damage index for the selected longitudinal reinforcements is not noticeable and it gradually increases by the end of the loading cycle.

The material responses under unidirectional loading are presented in Fig. 9(e-I). The materials' stressstrain curves for both horizontal directions show a considerably lower strain comparing to those observed under bidirectional MS excitation, as it was also mentioned by Zeris et al. [28]. Comparing Fig. 9(b, $f$ and j), it is evident that in this example the buckling of the South-West (SW) longitudinal reinforcement only occurs under bidirectional loading and the values of fatigue damage index are slightly higher in comparison to unidirectional loading.

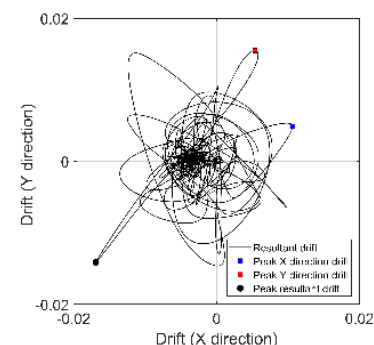

(a)

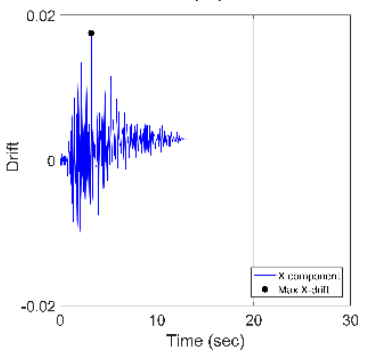

(e)

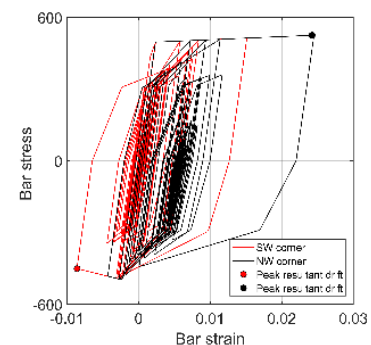

(b)

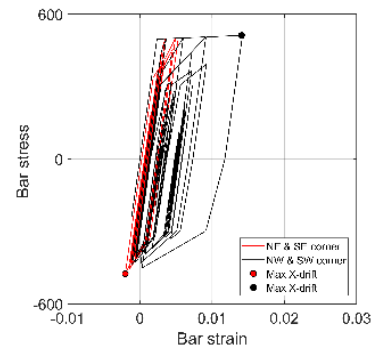

(f)

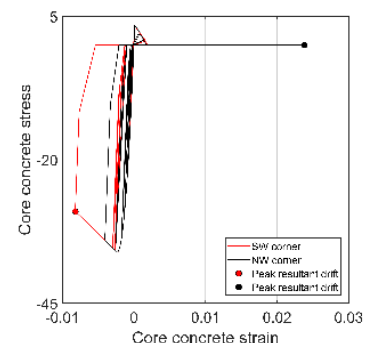

(c)

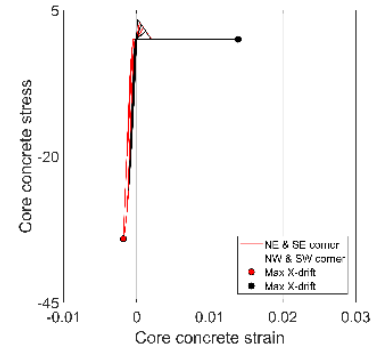

(g)

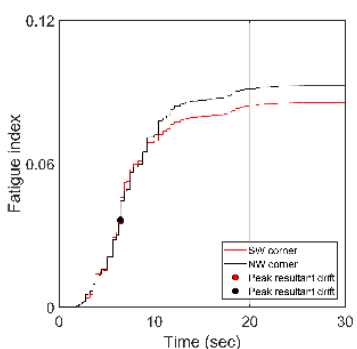

(d)

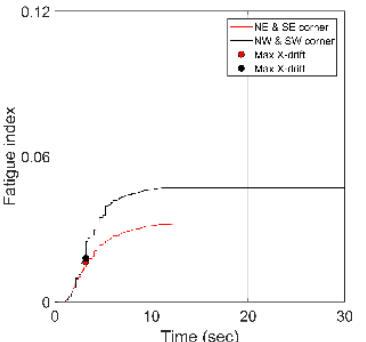

(h) 


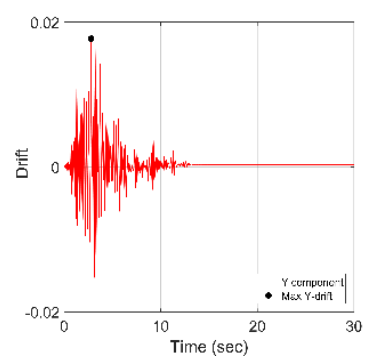

(i)

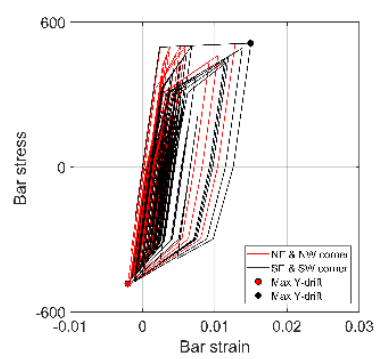

(j)

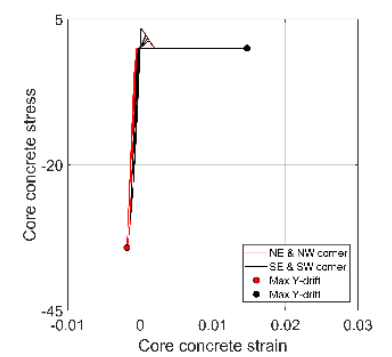

(k)

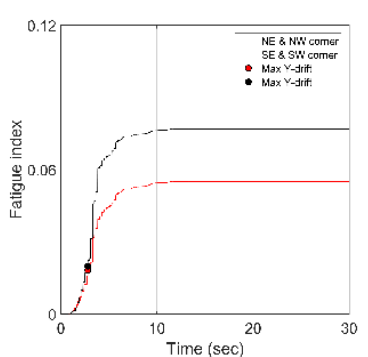

(I)

Fig. 9. Material response under bidirectional and unidirectional MS for rectangular RC column, (a, b, c, d) bidirectional drift, corner bar stress-strain curve, core concrete stress-strain, and fatigue damage index for corner bars; $(e, f, g, h) X$-direction drift time history, corner bar stress-strain under X-direction loading, core concrete stress-strain under $X$-direction loading, and fatigue damage index for corner bars under $X$-direction loading; (I, j, k and I) according to Y-direction response

Similar to the rectangular cross-section, the material response for circular RC column is presented in Fig. 10. The locations of the selected longitudinal reinforcements can be seen in Fig. 8, labelled as North, South, West and East sides. The comparison between bidirectional and unidirectional of circular cross-section suggests that, unlike the rectangular section, the circular section is less sensitive to bidirectional loading due to its omnidirectional stiffness/strength (i.e. azimuth independent structure). However, the fatigue damage index is slightly higher especially under unidirectional loading as the selected reinforcements at the edge is under higher amplitude of cyclic deformations (Fig 9(I)).

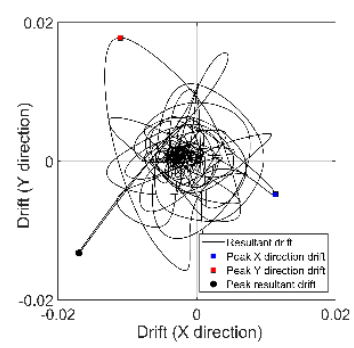

(a)

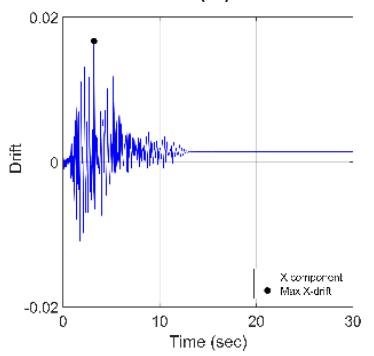

(e)

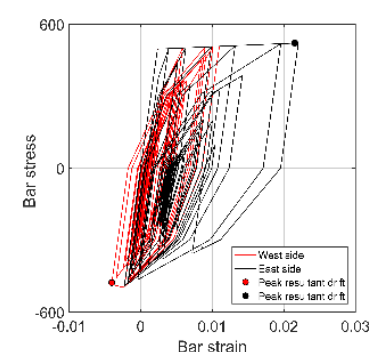

(b)

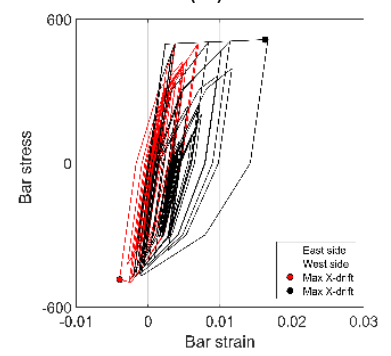

(f)

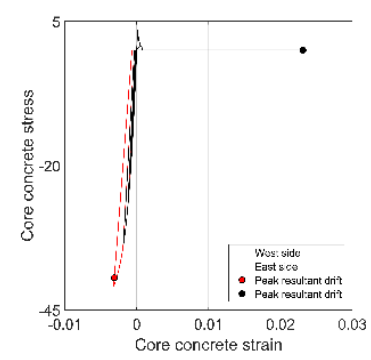

(c)

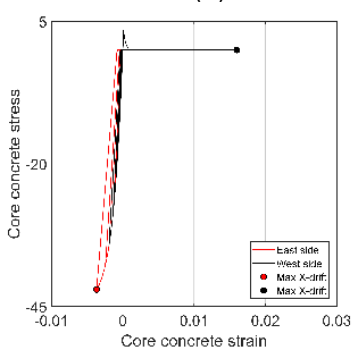

(g)

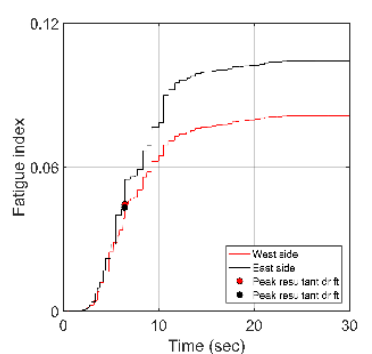

(d)

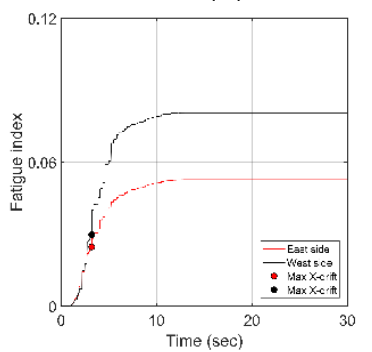

(h) 


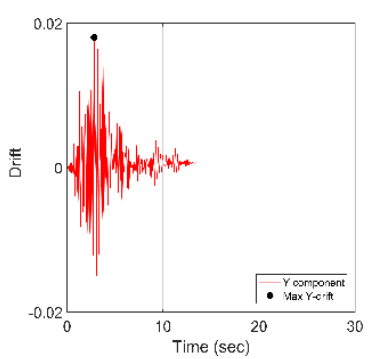

(i)

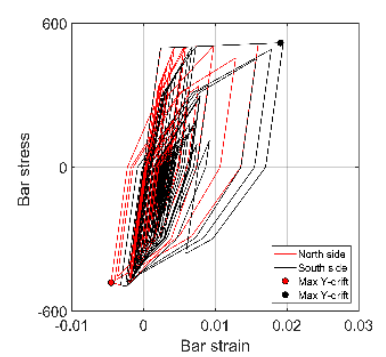

(j)

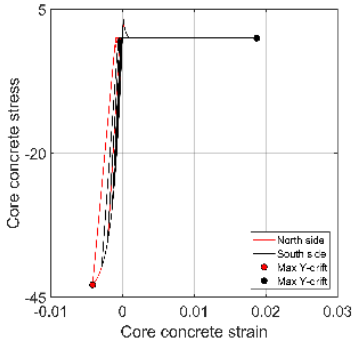

$(k)$

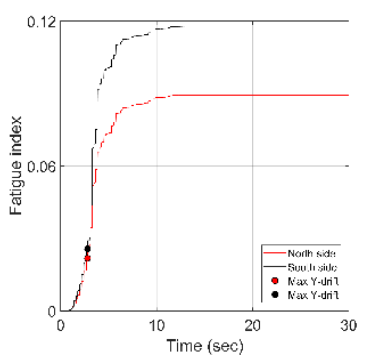

(I)

Fig. 10. Material response under bidirectional and unidirectional excitation for circular RC column; $(a, b, c, d)$ bidirectional drift, bar stress-strain curve, core concrete stress-strain, and fatigue damage index for bars; (e, $\mathrm{f}, \mathrm{g}, \mathrm{h}) \mathrm{X}$-direction drift time history, bar stress-strain under $\mathrm{X}$-direction loading, core concrete stress-strain under $\mathrm{X}$-direction loading, and fatigue damage index for bars under X-direction loading; (I, j, $\mathrm{k}$ and I) according to $Y$-direction response

To clarify and summarise the impact of bidirectional loading on the seismic assessment of RC columns, fragility curves (i.e. cumulative distribution function) for circular and rectangular columns under uni- and bidirectional loading are presented in Fig. 11. Three damage limit states based on modified damage index proposed by Mergos et al. [53] have been introduced. The median value for each damage state has been used to generate the fragility curves. Therefore, calculated damage with $\lambda_{\text {tot }}$ of $0.1,0.35$ and 0.75 are considered as minor, moderate and severe damage respectively. The physical definition of each damage state is provided in Table 2.

Fig. 11 shows that bidirectional loading has an impact on the fragility curves and the moderate and severe damage are more affected under bidirectional loading. Furthermore, the probability of severe damage for the rectangular column is higher in comparison to the circular column, suggesting that the rectangular columns are more sensitive to bidirectional loading. For example, at $\mathrm{Sa}\left(\mathrm{T}_{1}\right)=3 \mathrm{~g}$, for circular $\mathrm{RC}$ column, the probability of minor, moderate and severe damage under unidirectional excitation is $54.3 \%, 36.3 \%$ and $9.4 \%$ respectively, while the corresponding probability for the same damage levels under bidirectional excitation is $21 \%, 48.3 \%$ and $30.7 \%$, respectively. This shows that including bidirectional loading can significantly increase the probability of moderate and severe damage at the same $\mathrm{Sa}\left(\mathrm{T}_{1}\right)$ in comparison to unidirectional (more than double at severe damage limit). Likewise, at $\mathrm{Sa}\left(\mathrm{T}_{1}\right)=3 \mathrm{~g}$, for rectangular $\mathrm{RC}$ column, the probability of minor, moderate and severe damage under unidirectional excitation is $61.4 \%, 28.9 \%$ and $4.7 \%$ respectively, while the probability for the same damage levels under bidirectional excitation is $25.9 \%, 49.6 \%$ and $24.5 \%$, respectively. This shows the sensitivity of rectangular RC column at this $\mathrm{Sa}\left(\mathrm{T}_{1}\right)$ is approximately 5 times greater in comparison to unidirectional excitation at the severe damage limit. A similar trend of having a significant increase in the probability of moderate and severe damage is dominant for all range of $\mathrm{Sa}\left(\mathrm{T}_{1}\right)$. 


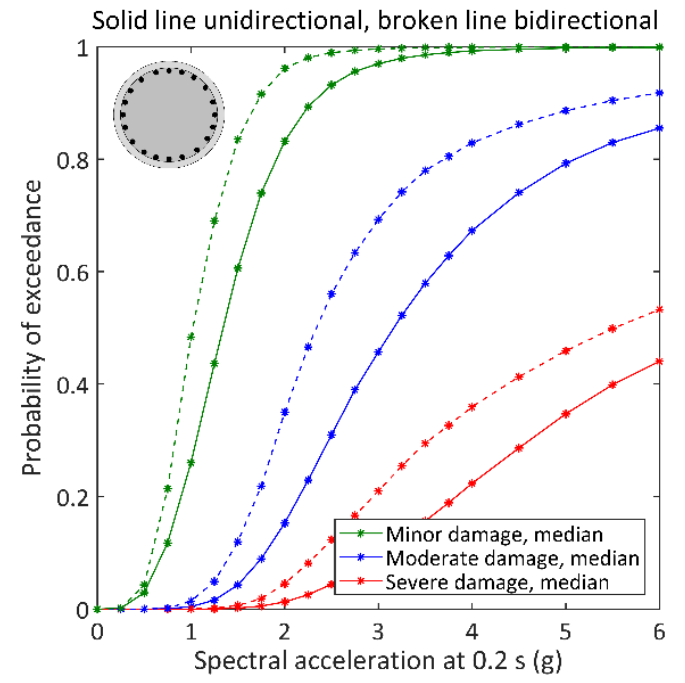

(a)

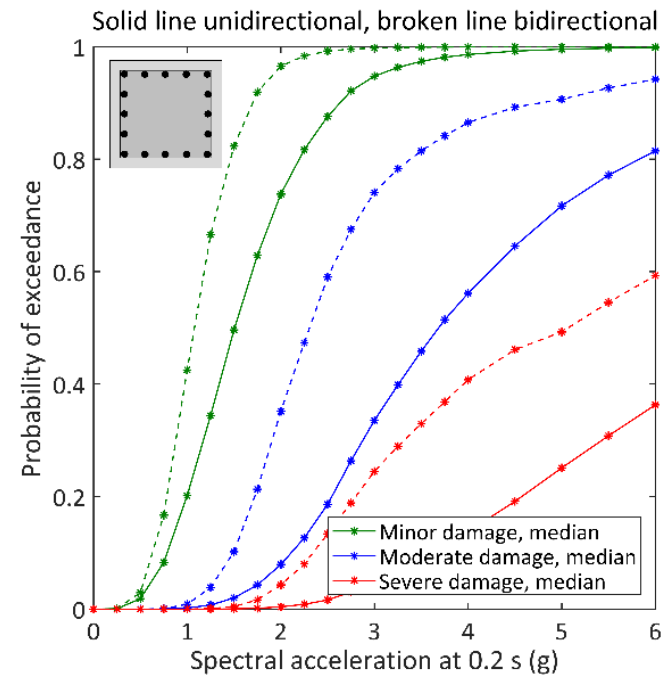

(b)

Fig. 11. Fragility curves for (a) circular and (b) rectangular columns under unidirectional and bidirectional single excitation (MS) loading

\subsection{Investigating the difference between bidirectional single and multiple excitations (2D MS-MSAS)}

The impact of aftershocks under unidirectional ground motion has been investigated by other researchers, examples can be found in [40-45]. To the authors' best knowledge, the current literature is based on 2D models excited under unidirectional loading. This paper is the first study to implement a holistic approach by integrating bidirectional loading with real MSAS sequences. The median IDA curve for MS and MSAS are presented in Fig. 12 for both circular and rectangular columns using the proposed modelling technique. From Fig. 12(a and b), it can be seen that under bidirectional excitation, aftershock reduces the capacity of the columns in particular for the resultant drifts of more than $3 \%$.

The fragility curves for RC columns under bidirectional MS and MSAS are presented in Fig. 12 (c and d). The minor damage for both cross-sections is slightly affected; however, the moderate and severe damages are remarkably affected under MSAS. For instance, the probability of minor, moderate and severe damage under MS for the circular column at $\mathrm{Sa}\left(\mathrm{T}_{1}\right)=3 \mathrm{~g}$, is $30.0 \%, 49.0 \%$ and $21.0 \%$ respectively. The corresponding probabilities for MSAS are $14.0 \%, 56.0 \%$, and $30.0 \%$ which shows a significant increase in moderate and severe damage under MSAS excitation (up to $40 \%$ for the severe damage). 


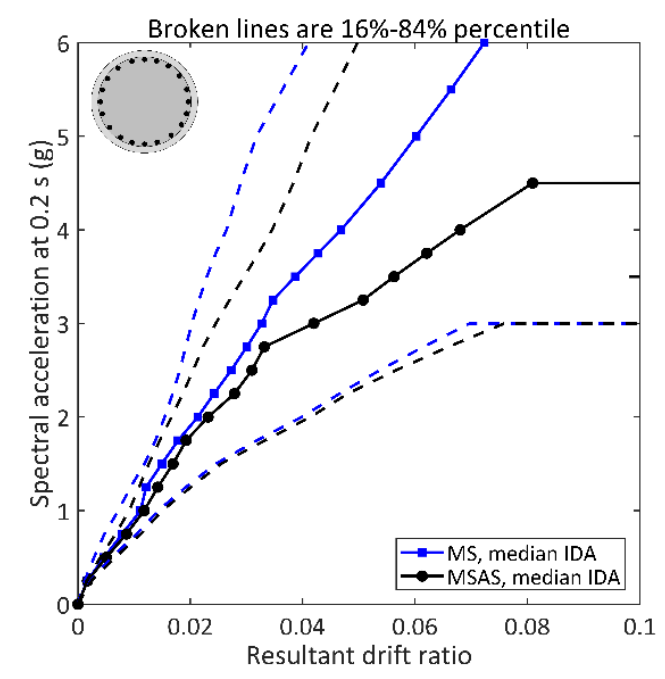

(a)

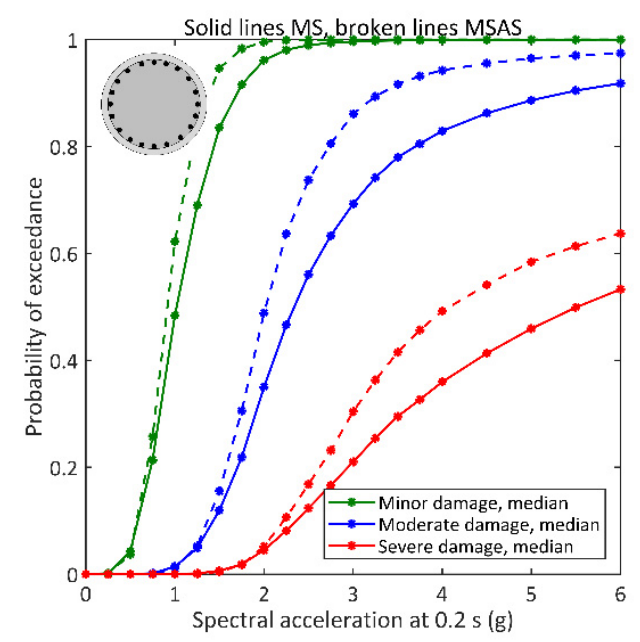

(c)

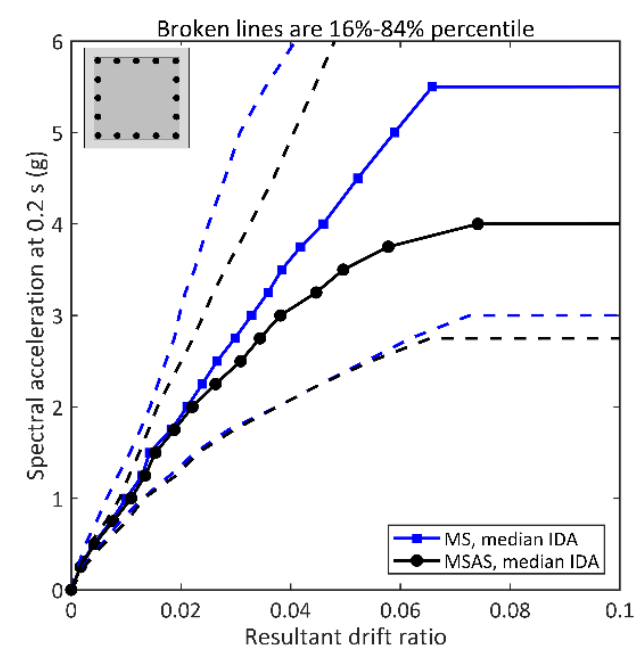

(b)

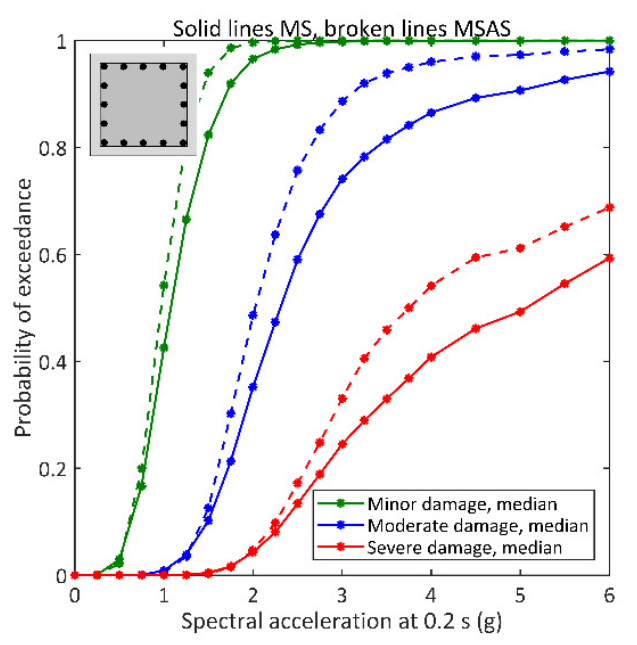

(d)

Fig. 12. Comparing the impact of bidirectional MS and MSAS; (a) median IDA for the circular column, (b) median IDA curve for the rectangular column, (c and d) fragility curves for circular and rectangular respectively

\subsection{Comparison between unidirectional and bidirectional multiple excitations (1D-2D MSAS)}

To investigate the impact of bidirectional loading on the failure mechanism of RC columns, the IDA results under uni- and bidirectional multiple excitations have presented in this section. Fig. 13 presents the IDA median curves, fatigue damage index and fragility curves for circular and rectangular RC columns under uniand bidirectional multiple excitations. It can be seen that bidirectional loading reduces the capacity of the RC column in particular for higher values of resultant drift as presented in Fig. 13 ( $a$ and b). The sensitivity of rectangular RC column is slightly higher to bidirectional loading. This could be because of corner bar buckling in rectangular cross-sections. Khaled et al. [14] and Kashani et al. [45] have also reported that at large displacements, buckling and fracture of corner bars in rectangular RC columns can happen, which is not a desirable response for an RC column. The maximum fatigue damage index for longitudinal corner bars under uni- and bidirectional MSAS is presented in Fig. 13 ( $c$ and d). For the rectangular column, the materials response (i.e. stress-strain and fatigue damage index of steel bars) of four corner bars are recorded. Under 
each IDA run, the peak fatigue damage index has been considered, similarly, the four-quadrant bars for the circular section have been recorded and the maximum is presented in Fig. 13(c). It can be concluded that the maximum fatigue damage index is higher under bidirectional loading. However, reflecting on the material responses that were presented in Figs. 9 and 10, the fatigue damage index is gradually increased by the end of the loading cycle. It is worth mentioning that the fatigue models are very sensitive to the calibration parameters and they are inherently uncertain, therefore careful interpretation is suggested when using such models in analytical simulation. Further experimental investigation regarding the impact of low-cycle fatigue and refining the accuracy of available models can improve the outcome of seismic performance assessment of RC structures.

To conclude and quantify the impact of bidirectional loading on RC columns, the fragility curves for both models under uni- and bidirectional MSAS excitation are presented in Fig. 13 (e and f). Probability of exceedance of minor damage is slightly affected by the direction of loading. However, the probability of exceedance of damage for moderate and severe damage levels are significantly affected by including bidirectional loading. This is more prominent for the RC column having a rectangular cross-section. 


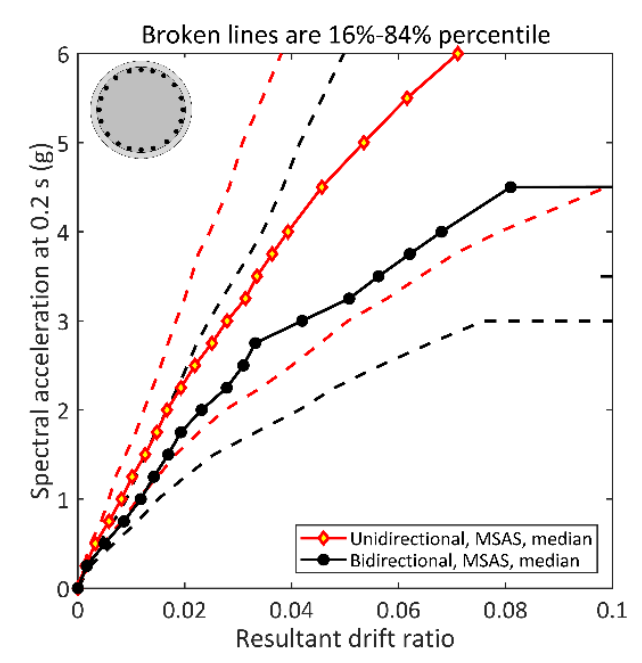

(a)

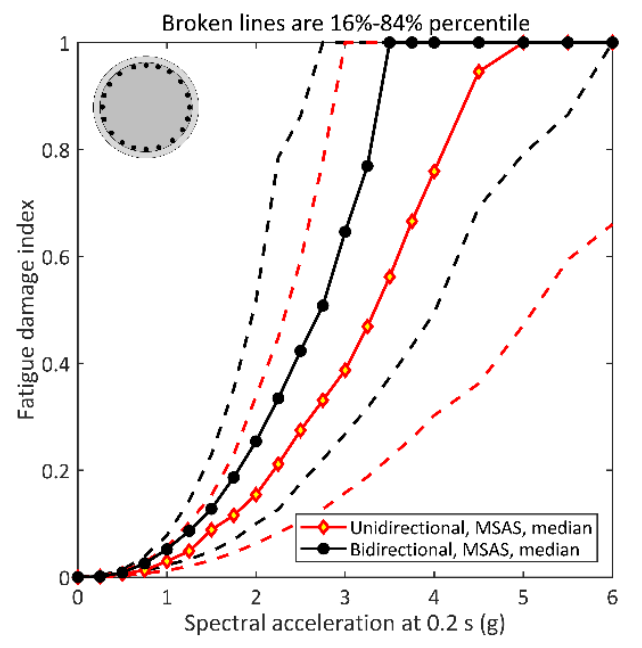

(c)

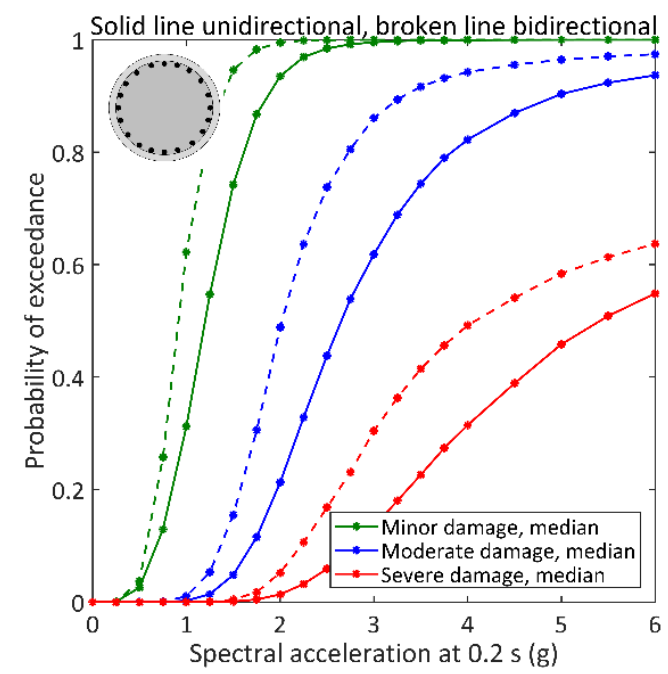

(e)

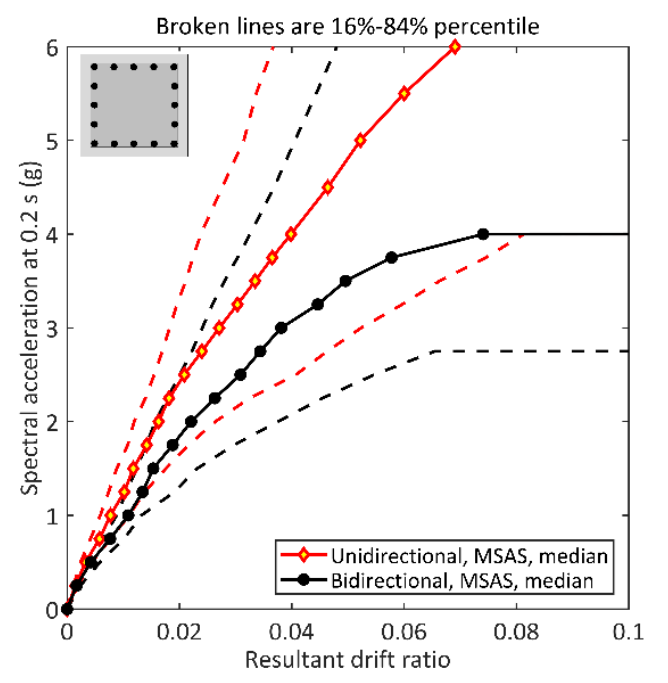

(b)

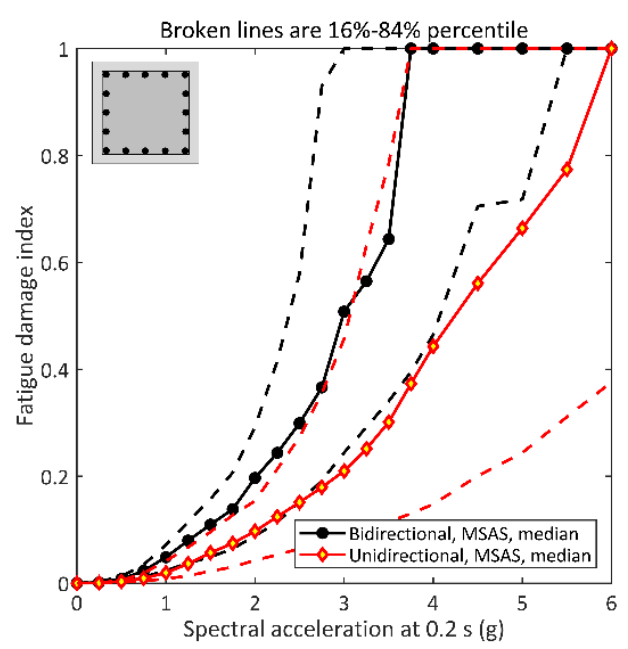

(d)

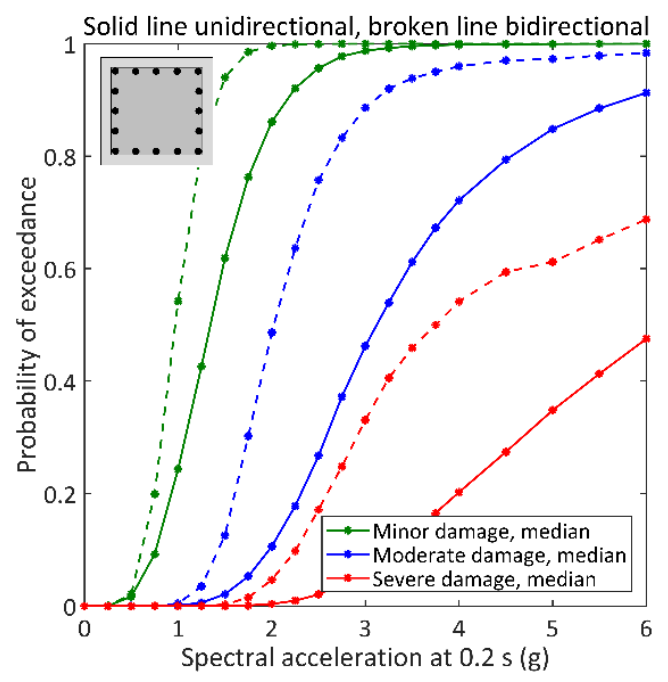

(f)

Fig. 13. Comparing the impact of unidirectional and bidirectional loading on circular and rectangular columns, ( $a$ and $b$ ) median IDA curves, ( $b$ and $c$ ) fatigue damage index and ( $c$ and d) fragility curves

For further clarification, the resultant drift ratio and the total damage index for circular and rectangular columns under uni- and bidirectional loading is presented in Fig. 14 (a and b). It can be seen that 
the rectangular column is more sensitive to bidirectional loading while the circular column is less affected by bidirectional loading. A damage contour plot for the angle of peak resultant deformation versus peak resultant drift is presented in Fig. 14(c and d). The damage is gradually increased independent to the angle of peak resultant drift for the circular column, while for the rectangular column the damage at 45 degree reaches to unity in lower resultant drift ratios. It must be noted that Fig. 14(c) is associated with a square cross-section. The angle of the maximum resultant drift (i.e. the neutral axis) is for rectangular sections having various width to height ratio. Therefore, the significance of bidirectional loading might be diverse under different crosssection geometry.

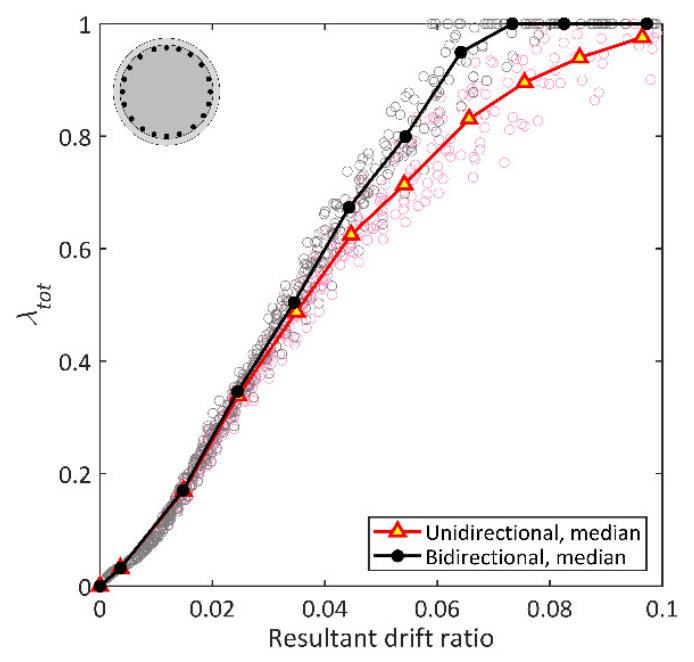

(a)

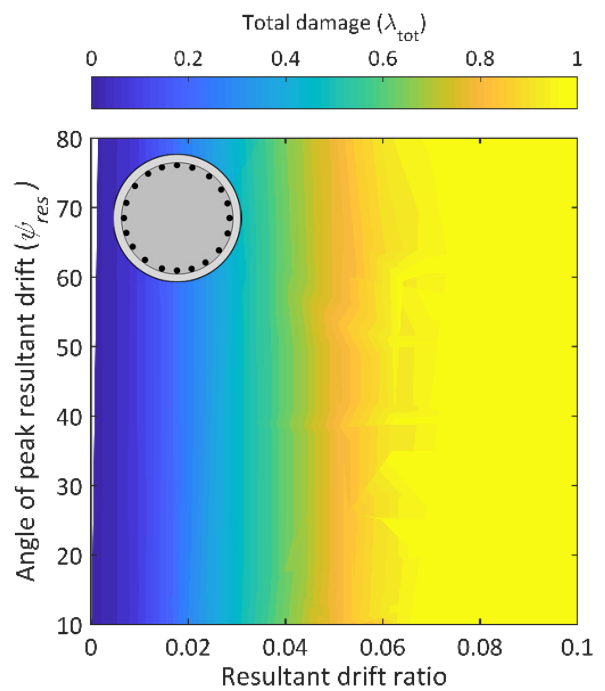

(c)

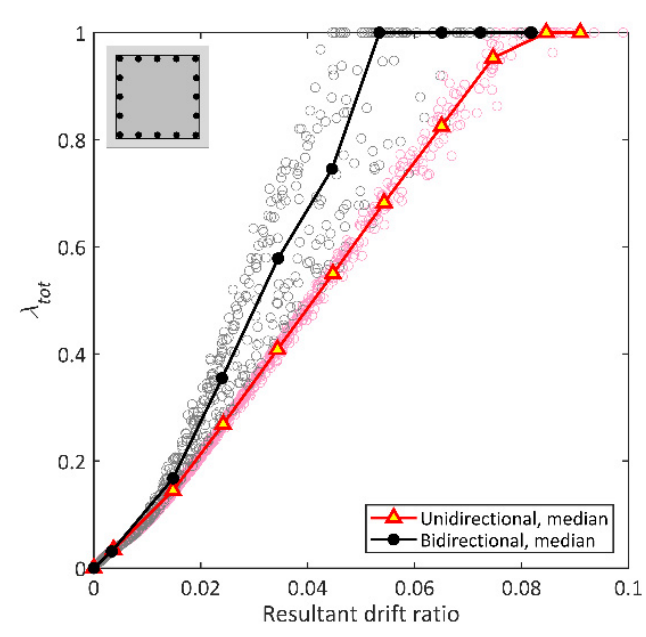

(b)

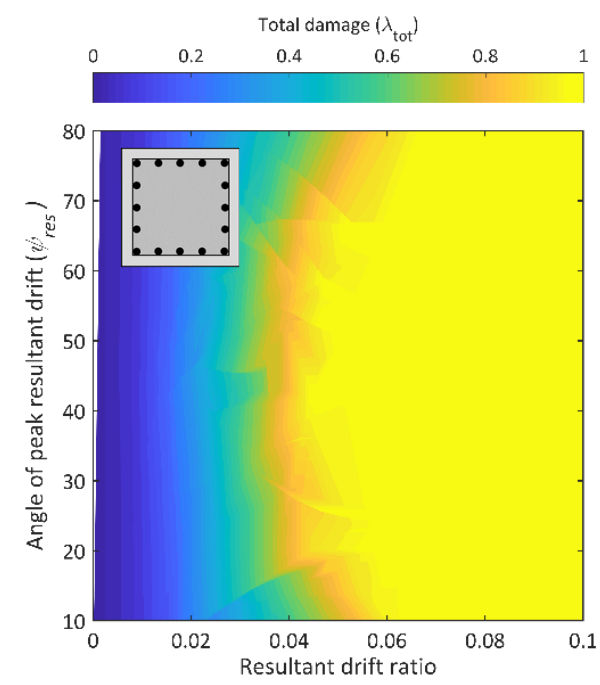

(d)

Fig. 14. Impact of unidirectional and bidirectional loading (a and b) total damage index versus resultant drift ratio, (c and d) damage contour-plot for the angle of peak resultant drift versus resultant drift 


\section{Conclusion}

This paper investigates the impact of bidirectional multiple excitations on the seismic performance of circular and rectangular RC columns. An advanced FE model which is capable of simulating multiple degradation mechanisms of RC members has been used. The model accounts for bar buckling, low-cycle fatigue and bondslippage which experimentally have been proven to be critical for RC members under bidirectional loading. To investigate the impact of low cycle fatigue degradation of longitudinal reinforcements, multiple excitations including real mainshock and aftershock have been considered. Moreover, an advanced damage index is implemented to quantify the various sources of damage including flexural, shear and bond-slip. A unique set of as-recorded real mainshock-aftershock sequences has been selected by using conditional means spectrum that reflects the seismicity of the specifically chosen site in the output of this paper. All of the above-mentioned aspects (i.e. structural modelling technique, cross-sectional geometry, inclusive damage index, accurate ground motion selection) make this study a comprehensive investigation regarding the impact of bidirectional behaviour of RC columns. However, it is important to clarify that the findings of this study are only valid for the selected cantilever columns, and ground motion records; and therefore, no generalised conclusion is the intention of this study. A comprehensive study has been planned to investigate the impact of longitudinal reinforcement's ratio, the volumetric ratio of transverse reinforcements and the axial force ratio for RC columns under bidirectional loading. The main findings of this paper are as follows:

- Bidirectional loading has a significant impact on the seismic performance of RC columns in comparison to unidirectional loading. For instance, the severe damage for the circular and rectangular column at $\mathrm{Sa}\left(\mathrm{T}_{1}\right)=3 \mathrm{~g}$ can be increased up to 2 and 5 times greater, respectively in comparison to unidirectional excitation.

- Rectangular column considered in this paper has a weak axis at 45 degrees is more sensitive to bidirectional loading in comparison to the circular column which has a similar stiffness/strength in all directions (omnidirectional stiffness structure).

- Low-cycle fatigue failure and longitudinal bar inelastic buckling have a noticeable contribution in damage of RC members, in particular, the corner bars of rectangular columns. However, the uncertainty of fatigue material models must be addressed when interpreting the outputs. Further research is warranted to calibrate the fatigue material model parameters to represent the strength reduction more realistically.

- Aftershock induces more damage in both the studied columns and increases the probability of collapse.

- The combined local damage index modified to be used for bidirectional loading can successfully predict the damage of RC members under flexural, bond-slip and shear damage.

\section{References}

[1] Low SS, Moehle JP. Experimental Study of Reinforced Concrete Columns Subjected to Multi-Axial Cyclic Loading. University of California, Berkeley, California; UCB/EERC-87/14. 1987. 
[2] Kogoma I, Hayashida T, Minowa C. Experimental studies on the collapse of RC columns during strong earthquake motions. Proceeding of $10^{\text {th }}$ World Conference on Earthquake Engineering, Hoboken, New Jersey, USA. 1996.

[3] Mo YL, Wang SJ. Seismic Behavior of RC Columns with Various Tie Configurations. J Struct Eng ASCE 1999; 126(10):1122-1130. https://doi.org/10.1061/(ASCE)0733-9445(2000)126:10(1122)

[4] Lehman DE, Moehle JP, Mahin SA, Calderone AC, Henry H. Experimental Evaluation of Seismic Design Provisions for Circular Reinforced Concrete Columns. J Struct Eng ASCE 2004;130(6):869-879. https://doi.org/10.1061/(ASCE)0733-9445(2004)130:6(869)

[5] Rodrigues $\mathrm{H}$, Varum $\mathrm{H}$, Arêde A, Costa A. A comparative analysis of energy dissipation and equivalent viscous damping of RC columns subjected to uniaxial and biaxial loading. Eng Struct 2012;35:149-164. https://doi.org/10.1016/i.engstruct.2011.11.014

[6] Wu S, Liu Z. A study on the sudden-crack-change of R/C column under dynamic vibration-strength and deformation. Proceeding of the $4^{\text {th }}$ U.S. National Conference on Earthquake Engineering, Earthquake Engineering Research Institute, El Cerrito, CA. 1990.

[7] Marante ME, Flórez-López J. Model of damage for RC elements subjected to bidirectional bending. Struct Eng 2002;24:1141-1152. https://doi.org/10.1016/S0141-0296(02)00044-5

[8] Marante ME, Florez-Lopez J. Three-dimensional analysis of reinforced concrete frames based on lumped damage mechanics. Int J Solids Struct 2003;40:5109-23. https://doi.org/10.1016/50020-7683(03)00258-0

[9] Sato Y, Ko H. Modeling of Reinforcement Buckling in RC Columns Confined with FRP. J Adv Concr Technol 2008; 6(1):195-204. https://doi.org/10.3151/jact.6.195

[10] Su J, Wang J, Bai Z, Wang W, Zhao D. Influence of reinforcement buckling on the seismic performance of reinforced concrete columns. Struct Eng 2015;103:174-188.

https://doi.org/10.1016/i.engstruct.2015.09.007

[11] Stewart JP, Abrahamson NA, Atkinson GM, Baker JW, Boore DM, Bozorgnia Y, Campbell KW, Comartin CD, Idriss IM, Lew M, Mehrain M, Moehle JP, Naeim F, Sabol TA. Representation of Bidirectional Ground Motions for Design Spectra in Building Codes. Earthq Spectra 2011;27(3):927-937, https://doi.org/10.1193/1.3608001

[12] Rodrigues $H$, Varum $H$, Arêde A, Costa A. Behaviour of reinforced concrete column under biaxial cyclic loading - state of the art. Int J Adv Struct Eng 2013;10:1-12. https://doi.org/10.1186/2008-6695-5-4

[13] Solberg K, Mashiko N, Mander JB, Dhakal RP. Performance of a Damage-Protected Highway Bridge Pier. J Struct Eng ASCE 2009;135:469-478. https://doi.org/10.1061/(ASCE)0733-9445(2009)135:5(469)

[14] Khaled A, Massicotte B, Tremblay R. Cyclic Testing of Large-Scale Rectangular Bridge Columns under Bidirectional Earthquake Components. J Bridge Eng ASCE 2011;16(3):351-363. https://doi.org/10.1061/(ASCE)BE.1943-5592.0000162.

[15] Rodrigues H, Arêde A, Varum H. Damage evolution in reinforced concrete columns subjected to bidirectional loading. Bull Earthq Eng 2013;11(5):1517-1540. https://doi.org/10.1007/s10518-013-94392

[16] Rodrigues H, Arêde A, Varum H, Costa AG. Experimental evaluation of rectangular reinforced concrete column behaviour under bidirectional cyclic loading. Earthquake Eng Struct Dyn 2013;42(2):239-259. https://doi.org/10.1002/eqe.2205 
[17] Rodrigues H, Furtado A, Arêde A. Behavior of Rectangular Reinforced-Concrete Columns under Biaxial Cyclic Loading and Variable Axial Loads. J Struct Eng ASCE 2016;142(1). https://doi.org/10.1061/(ASCE)ST.1943-541X.0001345

[18] Nojavan A, Schultz AE, Haselton C. A New Data Set for Full-Scale Reinforced Concrete Columns under Collapse-Consistent Loading Protocols. Earthq Spectra 2015;31(2),1211-1231. https://doi.org/10.1193/040314EQS047

[19] Lee CS, Han SW. Cyclic behaviour of lightly-reinforced concrete columns with short lap splices subjected to unidirectional and bidirectional loadings. Eng Struct, 2019; 189, 373-384, https://doi.org/10.1016/i.engstruct.2019.03.108.

[20] Han SW, Lee CS. Cyclic behavior of RC OMF beam-corner column joints under unidirectional and bidirectional loadings, Eng Struc, 2020; 224,111304, https://doi.org/10.1016/i.engstruct.2020.111304

[21] Raza S, Menegon SJ, Tsang H, Wilson JL. Force-displacement behavior of limited ductile high-strength RC columns under bidirectional earthquake actions, Eng Struct, 2020, 208, 110278, https://doi.org/10.1016/i.engstruct.2020.110278.

[22] Nakayama T, Igarashi K, Maruta M, Takashi M, Nakashima T, Suzuki N. Shaking table tests of reinforced concrete structures under bidirectional earthquake motions. Proceeding of the $11^{\text {th }}$ World Conference on Earthquake Engineering, Hoboken, New Jersey, USA, 1996.

[23] Nakayama T, Igarashi K, Hagiwara H. Bidirectional shaking table tests of a one fourth scale reinforced concrete space frame. Proceeding of the $12^{\text {th }}$ World Conference on Earthquake Engineering, Auckland, New Zeland, 2000.

[24] Hachem MM, Mahin SA, Moehle JP, Hachem MM, Mahin SA, Moehle JP. Performance of Circular Reinforced Concrete Bridge Columns under Bidirectional Earthquake Loading. Berkeley, Pacific Earthquake Engineering Research Center, 2003.

[25] Galé-Lamuela D, Donaire-Avila J, Escolano-Margarit D, González-Sanz G, Benavent-Climent A. Energy dissipation capacity of RC columns subjected to unidirectional and bidirectional seismic loading. Proceeding of the 7th International Conference on Computational Methods in Structural Dynamics and Earthquake Engineering, COMPDYN, Crete, Greece, 2019. https://doi.org/10.7712/120119.7078.19108

[26] Park YJ, Wen YK, Ang AHS. Random vibration of hysteretic systems under bi-directional ground motions. Earthquake Eng Struct Dyn 1986;14:543-557. https://doi.org/10.1002/eqe.4290140405

[27] Kitajima K, Adachi H, and Nakanishi, M. Response Analysis of Reinforced Concrete Columns Under BiDirectional Earthquake Motions: Response Characteristics of Reinforced Concrete Structures Under BiDirectional Earthquake Motions (II). J Struct Cons Eng 1994;59(461):85-94. https://doi.org/10.3130/aijs.59.85_1

[28] Zeris CA, Mahin SA. Behavior of Reinforced Concrete Structures Subjected to Biaxial Excitation. J Struct Eng ASCE 1991; 117(9):2657-2673. https://doi.org/10.1061/(ASCE)0733-9445(1991)117:9(2657)

[29] Lu D, Li Y, Wang Z, Wang G. Simulation of Seismic Behavior for RC Columns under Bidirectional. Appl Mech Mater 2012; 194:727-731. https://doi.org/10.4028/www.scientific.net/AMM.193-194.727

[30] Sengupta A, Quadery L, Sarkar S, Roy R. Influence of Bidirectional Near-Fault Excitations on RC Bridge Piers. J Bridge Eng ASCE 2016;21(7). https://doi.org/10.1061/(ASCE)BE.1943-5592.0000836

[31] American Association of State Highway and Transportation Officials (AASHTO). LRFD Bridge Design Specification, $2^{\text {nd }}$ Ed., Washington, D.C., USA, 1998. 
[32] American Association of State Highway and Transportation Officials (AASHTO). Guide specifications for LFRD seismic bridge design. $1^{\text {st }}$ Ed. Washington, D.C., USA, 2009.

[33] ASCE/SEI 7-10. Minimum design loads for buildings and other structures. Reston, VA: American Society of Civil Engineers, 2010.

[34] Applied Technology Council (ATC). Improved Seismic Design Criteria for California Bridges, ATC, Redwood City, California, USA, 1996.

[35] National Cooperative Highway Research Program (NCHRP). Comprehensive Specification for the Seismic Design of Bridges, NCHRP, $3^{\text {rd }}$ Draft, Washington, D.C., 2001.

[36] FHWA. Seismic retrofitting manual for highway structures: Part 1 - bridges. McLean, Virginia: Federal Highway Administration, 2006.

[37] Maleki S, Bisadi V. Orthogonal effects in seismic analysis of skewed bridges. J Bridge Eng ASCE 2006;11(1):122-30. https://doi.org/10.1061/(ASCE)1084-0702(2006)11:1(122)

[38] Kar D, Roy R. Seismic Behaviour of RC Bridge Piers under Bi-directional Excitations: Implications of Site Effects. J Earthq Eng 2016;22(2):303-331 https://doi.org/10.1080/13632469.2016.1233919

[39] Salami MR, Kashani MM, Goda K. Influence of advanced structural modeling technique, mainshockaftershock sequences, and ground-motion types on seismic fragility of low-rise RC structures. Soil Dyn Earthq Eng 2019;117(2):263-279. https://doi.org/10.1016/i.soildyn.2018.10.036

[40] Faisal A, Majid TA, Hatzigeorgiou GD. Investigation of story ductility demands of inelastic concrete frames subjected to repeated earthquakes. Soil Dyn Earthq Eng 2013;44(1):42-53, https://doi.org/10.1016/i.soildyn.2012.08.012

[41] Ebrahimian H, Jalayer F, Asprone D, Lombardi AM, Marzocchi W, Prota A, Manfredi G. A performancebased framework for adaptive seismic aftershock risk assessment. Earthq Eng Struct Dyn 2014;43(14): 2179-2197. https://doi.org/10.1002/eqe.2444

[42] Goda K, Tesfamariam S. Seismic risk management of existing reinforced concrete buildings in the Cascadia subduction zone. Nat Hazards Rev 2015;18(1):1-10. https://doi.org/10.1061/(ASCE)NH.1527$\underline{6996.0000206}$

[43] Raghunandan M, Liel AB, Luco N. Aftershock collapse vulnerability assessment of reinforced concrete frame structures Earthq Eng Struct Dyn 2015; 44(3): 419-439. https://doi.org/10.1002/eqe.2478

[44] Jeon JS, DesRoches R, Lowes LN, Brilakis I. Framework of aftershock fragility assessment-case studies: older California reinforced concrete building frames. Earthq Eng Struct Dyn 2015;44(15):2617-2636. https://doi.org/10.1002/eqe.2599

[45] Kashani MM, Ge X, Dietz MS, Crewe AJ, Alexander NA. Significance of non-stationary characteristics of ground-motion on structural damage: shaking table study. Bull Earthq Eng 2019;17:4885-4907. https://doi.org/10.1007/s10518-019-00668-3

[46] Vamvatsikos D, Cornell CA. Incremental dynamic analysis Earthq Eng Struct Dyn 2002; 31(3):491-514. https://doi.org/10.1002/eqe.141

[47] Kashani MM, Lowes LN, Crewe AJ, Alexander NA. Phenomenological hysteretic model for corroded reinforcing bars including inelastic buckling and low-cycle fatigue degradation. Comput Struct 2015;156: 58-71. https://doi.org/10.1016/j.compstruc.2015.04.005 
[48] Kashani MM, Lowes LN, Crewe AJ, Alexander NA. Nonlinear fibre element modelling of RC bridge piers considering inelastic buckling of reinforcement. Eng Struct 2016;116:163-177. https://doi.org/10.1016/i.engstruct.2016.02.051

[49] Kashani MM, Crewe AJ, Alexander NA. Structural capacity assessment of corroded RC bridge piers. Proceedings of the Institution of Civil Engineers - Bridge Engineering 2017;170(1):28-41. https://doi.org/10.1680/ibren.15.00023

[50] Kashani MM, Salami MR, Goda K, Alexander NA. Nonlinear flexural behaviour of RC columns including bar buckling and fatigue degradation Mag Concr Res 2017;70:231-247. https://doi.org/10.1680/jmacr.16.00495

[51] Afsar Dizaj E, Madandoust R, Kashani MM. Exploring the impact of chloride-induced corrosion on seismic damage limit states and residual capacity of reinforced concrete structures. Struct Infrastruct E 2018;14 (6):714-729. https://doi.org/10.1080/15732479.2017.1359631

[52] Afsar Dizaj E, Madandoust R, Kashani MM. Probabilistic seismic vulnerability analysis of corroded reinforced concrete frames including spatial variability of pitting corrosion. Soil Dyn Earthq Eng 2018; 114: 97-112. https://doi.org/10.1016/j.soildyn.2018.07.013

[53] Mergos PE, Kappos AJ. A combined local damage index for seismic assessment of existing RC structures. Earthq Eng Struct Dyn 2013; 42:833-852. https://doi.org/10.1002/eqe.2247

[54] Afsar Dizaj E, Kashani MM. Numerical investigation of the influence of cross-sectional shape and corrosion damage on failure mechanisms of RC bridge piers under earthquake loading. Bull Earthquake Eng 2020. https://doi.org/10.1007/s10518-020-00883-3

[55] Baker J. Conditional mean spectrum: tool for ground-motion selection. J Struct Eng 2011;137(3):322-331. https://doi.org/10.1061/(ASCE)ST.1943-541X.0000215

[56] Berry M, Parrish M, Eberhard M. Performance database user's manual. PEER. 461 University of California, Berkeley, USA, 2004. https://nisee.berkeley.edu/spd/

[57] Dhakal RP, Maekawa K. Reinforcement stability and fracture of cover concrete in reinforced concrete members. J Struct Eng 2002;128(10):1253-1262. https://doi.org/10.1061/(ASCE)07339445(2002)128:10(1253)

[58] McKenna F. OpenSees: a framework for earthquake engineering simulation. Comput Sci Eng 2011; 13(4): 58-66. https://doi.org/10.1109/MCSE.2011.66

[59] Menegotto M, Pinto PE. Method of analysis of cyclically loaded RC plane frames including changes in geometry and nonelastic behavior of elements under normal force and bending. In Preliminary Report, 13. Zurich: IABSE; 1973.

[60] Bauschinger J. Variations in the elastic limit of iron and steel. J Iron Steel Inst 1887;12(1):442-444.

[61] Manson SS. Fatigue: A complex subject-Some simple approximations. Exp Mech 1965;5:193-226. https://doi.org/10.1007/BF02321056

[62] Kashani MM, Barmi AK, Malinova VS. Influence of inelastic buckling on low-cycle fatigue degradation of reinforcing bars. Constr Build Mater 2015;94,644-655. https://doi.org/10.1016/i.conbuildmat.2015.07.102

[63] Scott BD, Park R, Priestley MJN. Stress-strain behavior of concrete confined by overlapping hoops at low and high strain rates. ACI J 1982;79 (1):13-27. 
[64] Popovics S. A numerical approach to the complete stress strain curve for concrete. Cem Concr Res 1988;3(5):583-599.

[65] Karsan ID, Jirsa JO. Behaviour of concrete under compressive loading. J Struct Div 1969; 95(12):2543-2564.

[66] Mander JB, Priestley MJN, Park R. Theoretical stress-strain model for confined concrete. J Struct Eng 1988; 114(8):1804-1825. https://doi.org/10.1061/(ASCE)0733-9445

[67] Zhao J, Sritharan S. Modeling of strain penetration effects in fiber-based analysis of reinforced concrete structures. ACl struct J 2007;104(2):133-141.

[68] Hancock J, Bommer JJ. A state-of-knowledge review of the influence of strong-motion duration on structural damage. Earthq Spectra 2006;22(3):827-845. https://doi.org/10.1193/1.2220576

[69] Kappos AJ. Seismic damage indices for RC buildings: evaluation of concepts and procedures. Earthq Eng Struct Dyn 2005; 1(1):78-87. https://doi.org/10.1002/pse.2260010113

[70] Rodriguez ME. Evaluation of a proposed damage index for a set of earthquakes. Earthq Eng Struct Dyn 2015;44:1255-1270. https://doi.org/10.1002/eqe.2512

[71] Park YJ, Ang HS. Seismic damage model for Reinforced concrete. J Struct Eng ASCE 1985;111(4):722-739. https://doi.org/10.1061/(ASCE)0733-9445(1985)111:4(722)

[72]Roy A, Bhattacharya G, Roy R. Maximum credible damage of RC bridge pier under bi-directional seismic excitation for all incidence angles. Struct Eng 2017;152(1):251-273. https://doi.org/10.1016/i.engstruct.2017.09.008

[73] Roy A, Santra A, Roy R. Estimating seismic response under bi-directional shaking per uni-directional analysis: Identification of preferred angle of incidence. Soil Dyn Earthq Eng 2018;106:163-181. https://doi.org/10.1016/j.soildyn.2017.12.022

[74] Mergos PE, Kappos AJ. A gradual spread inelasticity model for R/C beam-columns, accounting for flexure, shear and anchorage slip. Eng Struct 2012;44, 94-106. https://doi.org/10.1016/j.engstruct.2012.05.035

[75] Sezen H, Moehle JP. Shear strength model for lightly reinforced concrete columns, J. Struct. Eng. ASCE 2004;130(11) 1692-1703. https://doi.org/10.1061/(ASCE)0733-9445(2004)130:11(1692)

[76] Sezen H, Chowdhury T. Hysteretic Model for Reinforced Concrete Columns Including the Effect of Shear and Axial Load Failure. J Struct Eng ASCE 2009;135(2)139-146.https://doi.org/10.1061/(ASCE)07339445(2009)135:2(139)

[77] Sae-Long W, Limkatanyu S, Prachasaree W, Horpibulsuk S, Panedpojaman P. Nonlinear Frame Element with Shear-Flexure Interaction for Seismic Analysis of Non-Ductile Reinforced Concrete Columns. Int J Concr Struct Mater 2019; 13(32). https://doi.org/10.1186/s40069-019-0343-2

[78] Abrahamson NA, Silva WJ, Kamai R. Summary of the ASK14 ground motion relation for active crustal regions. Earthq Spectra 2014;30 (3):1025-1055. https://doi.org/10.1193/070913EQS198M

[79] Chiou BSJ, Youngs RR. Update of the Chiou and Youngs NGA Model for the Average Horizontal Component of Peak Ground Motion and Response Spectra. Earthq Spectra 2014;30(3):1117-1153. https://doi.org/10.1193/072813EQS219M

[80] Campbell KW, Bozorgnia Y. NGA-West2 Ground Motion Model for the Average Horizontal Components of PGA, PGV, and 5\% Damped Linear Acceleration Response Spectra. Earthq Spectra 2014; 30(3): 1087-1115. https://doi.org/10.1193/062913EQS175M 
[81] Boore DM, Stewart JP, Seyhan E, Atkinson GM. NGA-West2 Equations for Predicting PGA, PGV, and 5\% Damped PSA for Shallow Crustal Earthquakes. Earthq Spectra 2014;30(3):1057-1085. https://doi.org/10.1193/070113EQS184M

[82] Idriss M. An NGA-West2 Empirical Model for Estimating the Horizontal Spectral Values Generated by Shallow Crustal Earthquakes. Earthq Spectra 2014;30(3):1155-1177. https://doi.org/10.1193/070613EQS195M

[83] Goda K, Taylor CA. Effects of aftershocks on peak ductility demand due to strong ground motion records from shallow crustal earthquakes. Earthq Eng Struct Dyn 2012;41(15):2311-2330. https://doi.org/10.1002/eqe.2188

[84] Baker JW, Cornell CA. Vector-valued Intensity Measures Incorporating Spectral Shape for Prediction of Structural Response. J Earthq Eng 2008;12(4):534-554. https://doi.org/10.1080/13632460701673076 